\title{
Output Error Estimates and Mesh Refinement in Aerodynamic Shape Optimization
}

\section{MARIAN NEMEC}

Science \& Technology Corp.

\section{MiCHAEL J. AfTOSMIS}

NASA

ADVANCED SUPERCOMPUTING DIVISION NASA AMES RESEARCH CENTER

AIAA Paper 2013-0865

51st AIAA Aerospace Sciences Meeting January 9, 2013 


\section{Motivation}

- Success of output error estimation and adaptive mesh refinement in goaloriented simulations

- Automatic and user-independent production databases

- Challenges of simulation-based design

- High CFD expertise

- Reliable mesh generation, long setup time

- High cost due to repeated evaluation of objectives on fine, hand-crafted meshes or high uncertainty due to inappropriate meshes

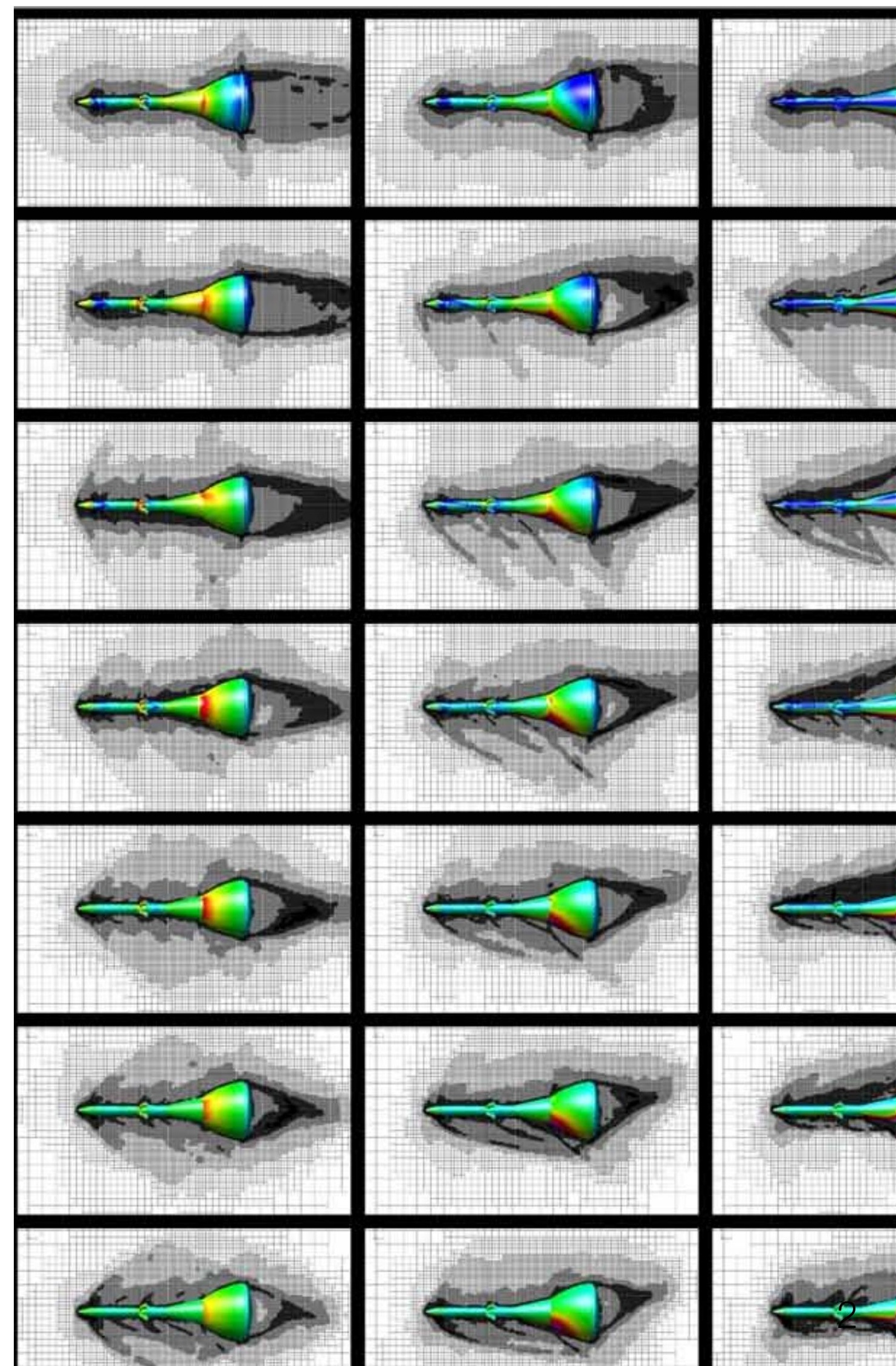




\section{Objectives}

\section{Adaptive discretization of aerodynamic shape optimization problems}

\section{Accuracy}

- Improve design confidence

- Direct control over objective function discretization error

\section{Automation}

- Reduce level of CFD expertise

- Eliminate the requirement to hand-craft general meshes appropriate for all candidate designs

- Shorten problem setup time

\section{Progress toward improved efficiency}

- Reduce cost by systematically increasing the depth of refinement as the design improves

- Progressive optimization strategy

- Investigate challenges of dynamic error control 


\section{Previous Work - Infrastructure}

1. Embedded-boundary Cartesian mesh method

- Arbitrarily complex domains, efficient and accurate

- Irregularity confined to body intersecting cells

2. Incremental strategy for h-refinement

\section{Adjoints}

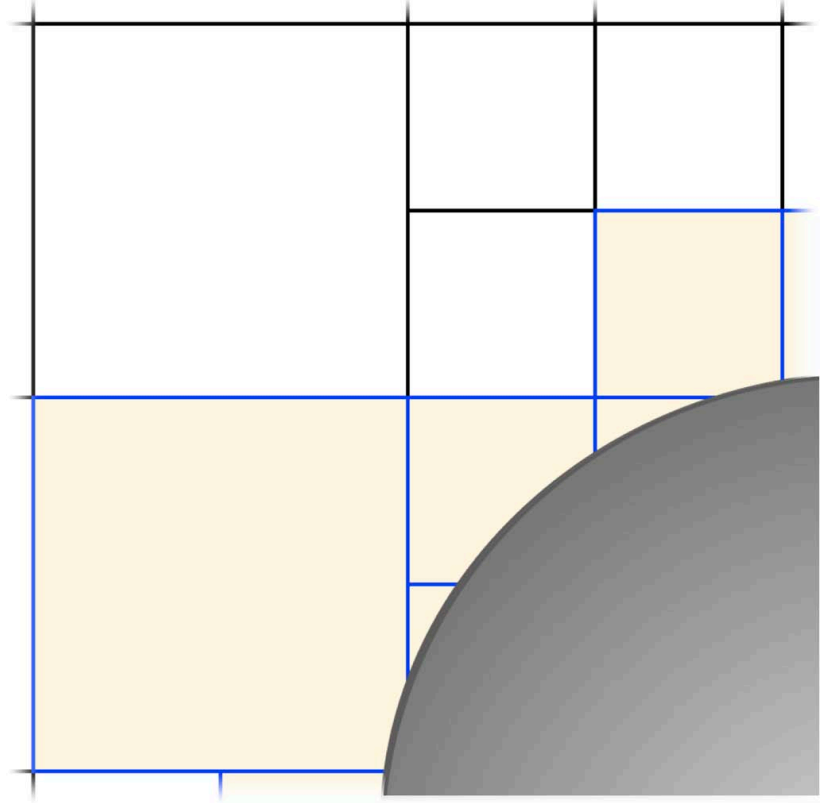

3. Aerodynamic shape optimization

- Gradient computation

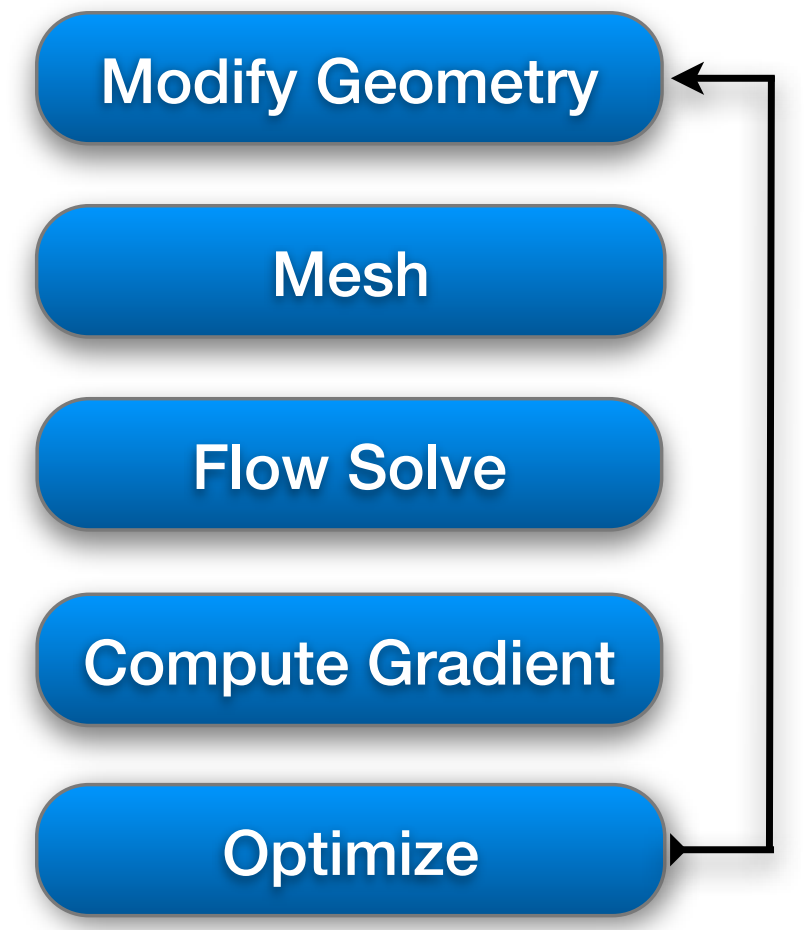

See AIAA Paper 2013-0543 (Smith et al.) for applications
4. Output error estimates

- Adaptive mesh refinement

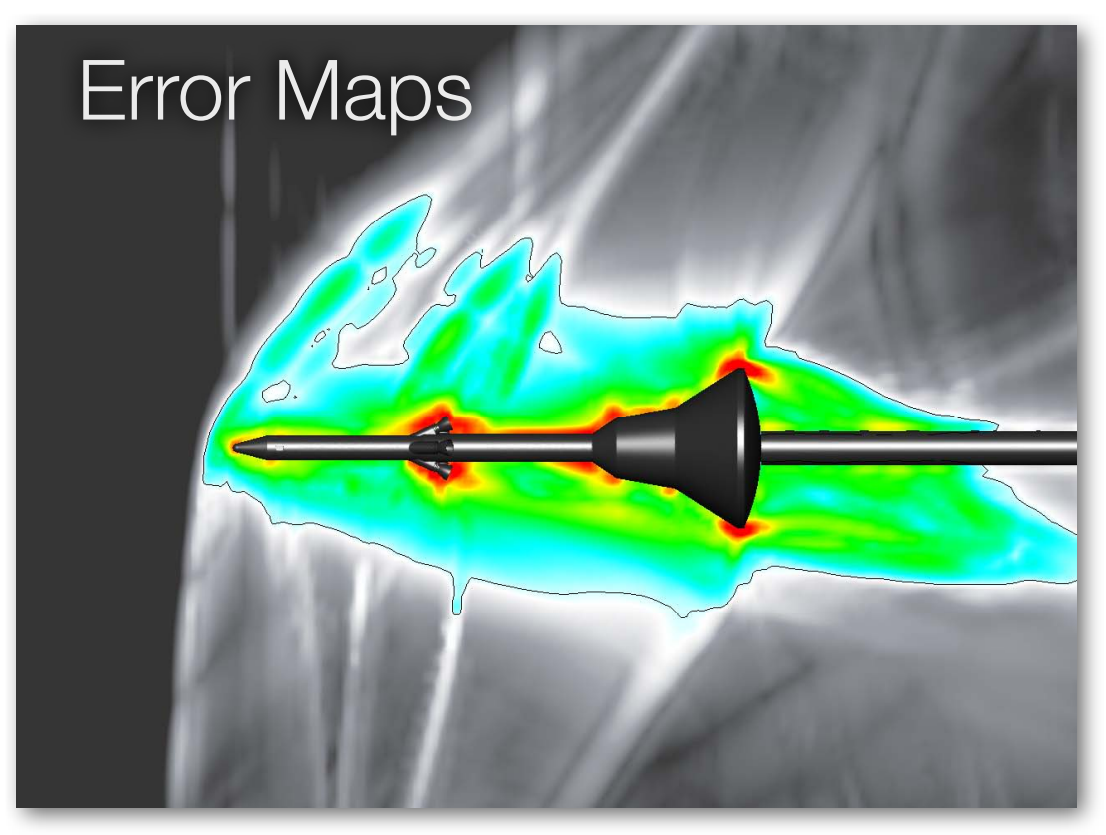




\section{Optimization: Discrete Formulation}

Modify Geometry

\section{Mesh \& Flow Solve}

\section{Evaluate Objective}

Compute Gradient

Optimize

$$
\begin{gathered}
\min _{X} J(X, \mathbf{Q}) \\
\text { subject to } \\
R(X, \mathbf{Q})=0 \quad \forall X \in \Omega
\end{gathered}
$$

- Steady Euler equations

- Gradient-based optimization $\frac{\mathrm{d} J}{\mathrm{~d} X}$

- BFGS

- SNOPT

- Shape optimization

$$
\mathbf{M}=f[\mathbf{T}(X)]
$$




\section{Role of Adjoints}

\section{Gradients}

$$
\begin{aligned}
& J=f(X, \mathbf{Q}) \\
& H \quad \text { e.g. } C_{D}+\left(C_{L}-C_{L}^{*}\right)^{2}
\end{aligned}
$$$$
\frac{\mathrm{d} J}{\mathrm{~d} X}=\frac{\partial J}{\partial X}+\frac{\partial J}{\partial \mathbf{Q}} \frac{\mathrm{d} \mathbf{Q}}{\mathrm{d} X}
$$$$
0=\frac{\partial \mathbf{R}}{\partial X}+\frac{\partial \mathbf{R}}{\partial \mathbf{Q}} \frac{\mathrm{d} \mathbf{Q}}{\mathrm{d} X}
$$

$$
\left[\frac{\partial \mathbf{R}}{\partial \mathbf{Q}}\right]^{\mathrm{T}} \psi=\frac{\partial J}{\partial \mathbf{Q}}
$$

\section{Error Estimates}

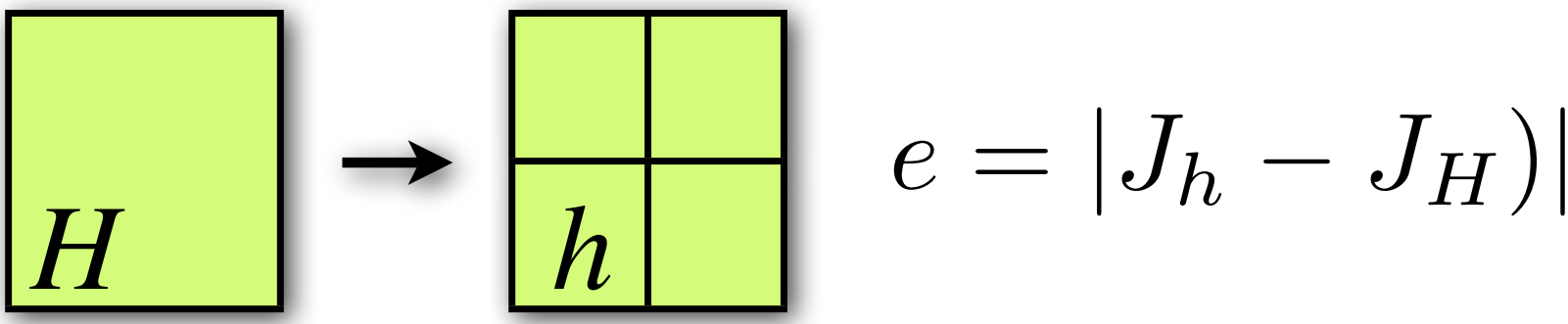

$$
\begin{aligned}
J_{h} & \approx J_{h}\left(\mathbf{Q}_{H}\right)+\frac{\partial J\left(\mathbf{Q}_{H}\right)}{\partial \mathbf{Q}} \Delta \mathbf{Q} \\
0 & \approx R_{h}\left(\mathbf{Q}_{H}\right)+\frac{\partial R\left(\mathbf{Q}_{H}\right)}{\partial \mathbf{Q}} \Delta \mathbf{Q}
\end{aligned}
$$

$$
\frac{\mathrm{d} J}{\mathrm{~d} X}=\frac{\partial J}{\partial X}-\psi^{\mathrm{T}} \frac{\partial \mathbf{R}}{\partial X}
$$

$$
J_{h} \approx J_{h}\left(\mathbf{Q}_{H}\right)-\psi^{\mathrm{T}} \mathbf{R}_{h}\left(\mathbf{Q}_{H}\right)
$$




\section{Role of Adjoints}

$$
\begin{aligned}
& \mathrm{M}_{\infty}=1.1, \alpha=-25^{\circ} \\
& J=C_{N}+0.2 C_{A}
\end{aligned}
$$

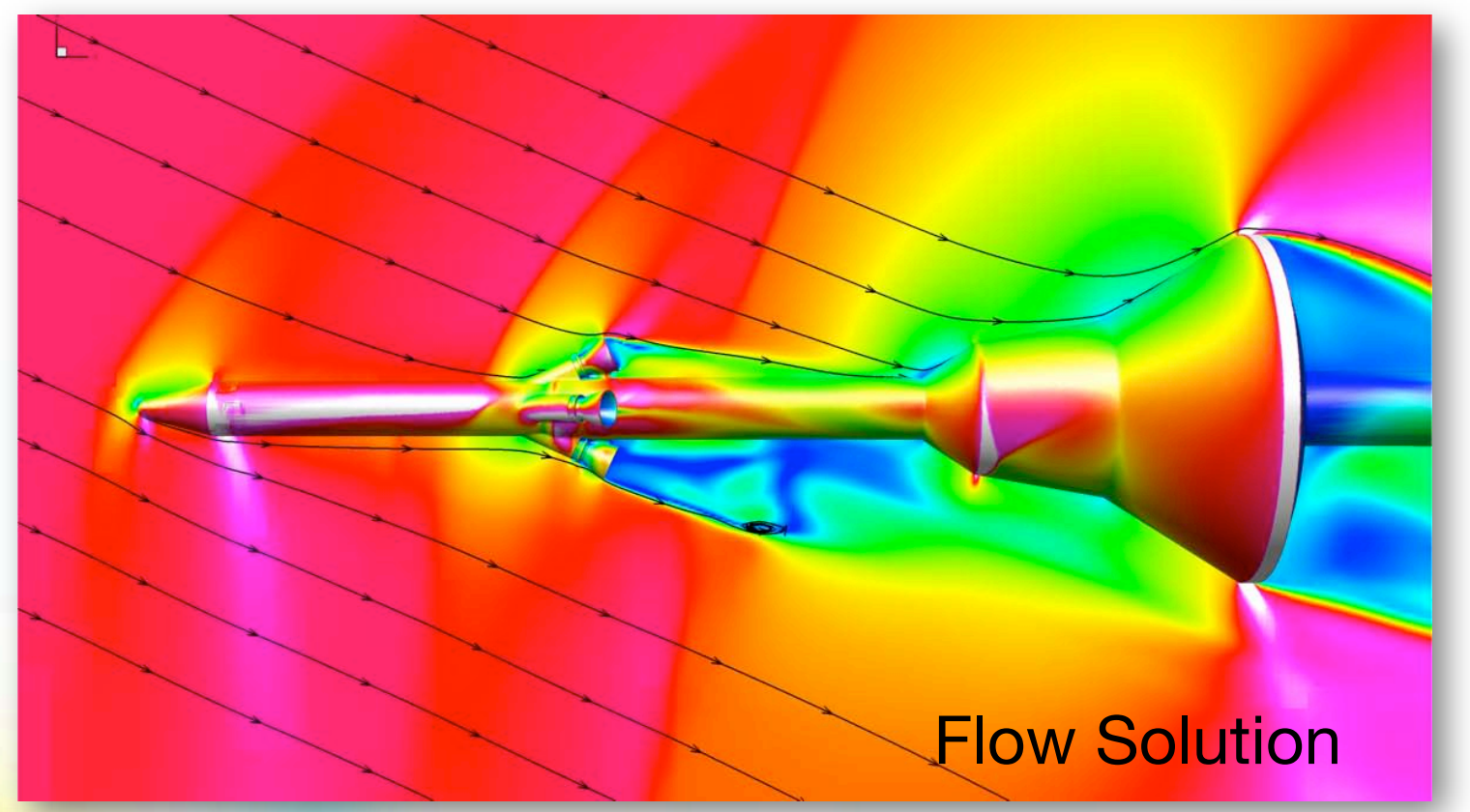

Not sensitive

Addition of mass increases functional

- Control problem

-Optimal shape design: adjust design variables to control the flow and improve performance

-Error analysis: adjust mesh refinement to control discretization errors 


\section{Linearization Details}

- Objective function gradient

$$
\frac{\mathrm{d} \mathcal{J}}{\mathrm{d} X}=\frac{\partial \mathcal{J}}{\partial X}+\frac{\partial \mathcal{J}}{\partial \mathbf{M}} \frac{\partial \mathbf{M}}{\partial \mathbf{T}} \frac{\partial \mathbf{T}}{\partial X}-\psi^{\mathrm{T}}\left(\frac{\partial \mathbf{R}}{\partial X}+\frac{\partial \mathbf{R}}{\partial \mathbf{M}} \frac{\partial \mathbf{M}}{\partial \mathbf{T}} \frac{\partial \mathbf{T}}{\partial X}\right)
$$

- Mesh sensitivities: infinitesimal perturbations are confined to cutcells
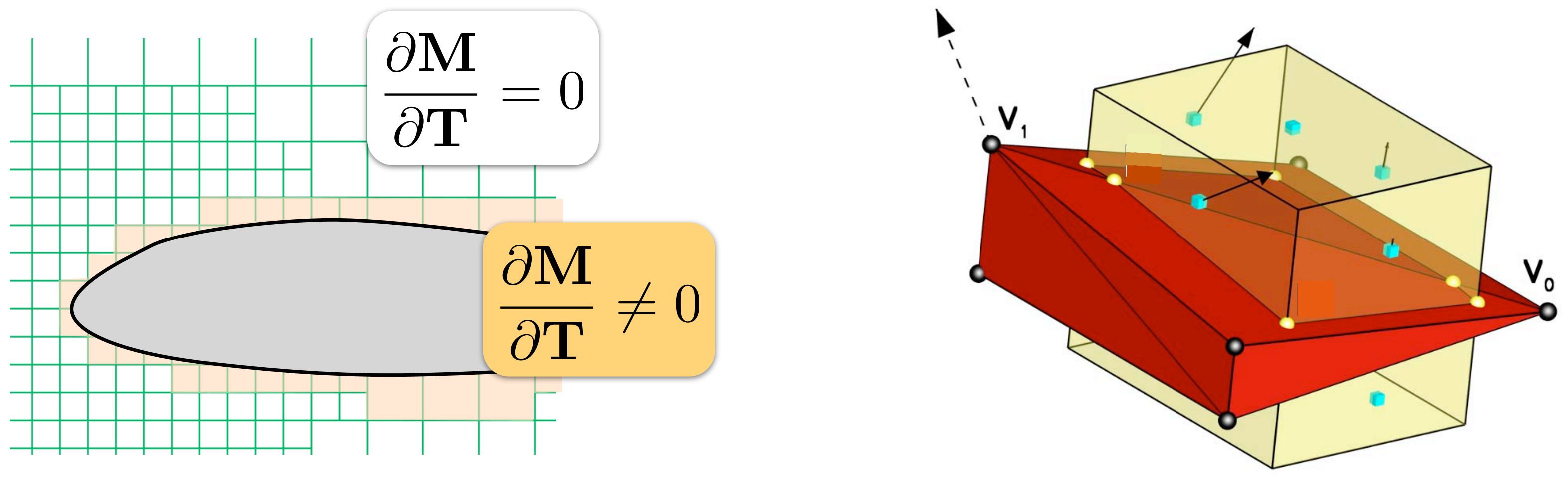

- Triangle to cut-cell connectivity established on-the-fly as the design evolves: triangulation connectivity and topology allowed to change 


\section{Error-Estimate Details}

$$
J\left(\mathbf{Q}_{h}\right) \approx J\left(\mathbf{Q}_{h}^{H}\right)-\left(\psi_{h}^{H}\right)^{\mathrm{T}} \mathbf{R}\left(\mathbf{Q}_{h}^{H}\right)-\left(\psi_{h}-\psi_{h}^{H}\right)^{\mathrm{T}} \mathbf{R}\left(\mathbf{Q}_{h}^{H}\right)
$$

- Bound on remaining error in each coarse cell $\mathrm{k}$

$$
e_{k}=\sum_{i=1}^{5}\left|\left(\psi_{\mathrm{Q}}-\psi_{\mathrm{L}}\right)^{\mathrm{T}} \mathbf{R}\left(\mathbf{Q}_{\mathrm{L}}\right)\right|_{i}
$$

Remaining Error

- Net functional error $E=\sum_{k=0}^{N} e_{k}$

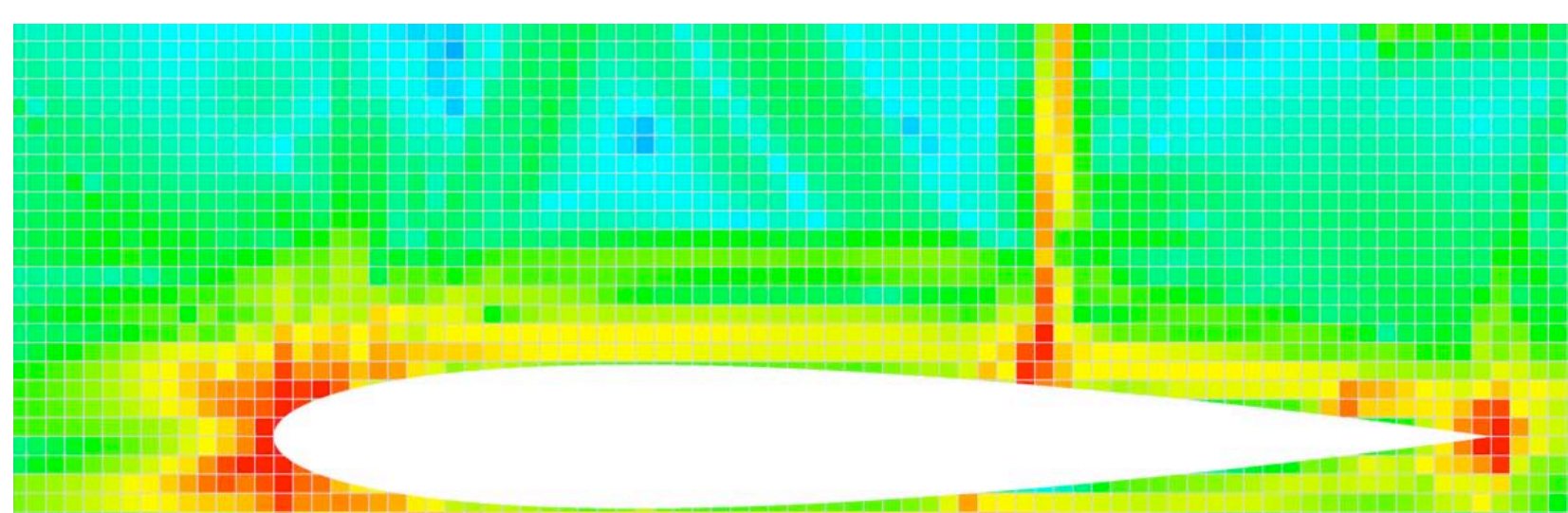

- Given a user specified tolerance TOL, refine until E $<$ TOL

- In practice, specify number of cycles, mesh-growth factor per cycle and cell-budget 


\section{Basic Framework Integration}

\section{Modify Geometry}

Initial Mesh

Adanto Calin

Adnet o Calin

Adapt \& Solve

Evaluate Objective

Compute Gradient

Optimize

- Multilevel parallelism

- Mesh sensitivities in stand-alone code

- In each design iteration, perform fixed (user specified) number of adaptations

- Fixed depth strategy

- Very robust and precise control over computational resources

- May be inefficient

- Integration into existing, fixed mesh, optimization framework

- Build sequence of adapted meshes

- Pass values of objective and gradient from finest mesh to optimizer

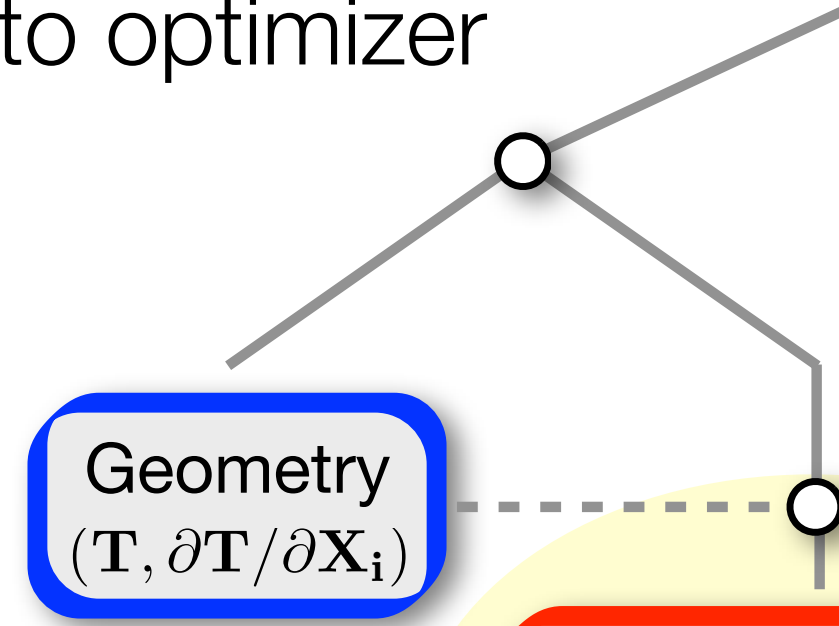

Adaptive Meshing Flow \& Adjoint Analysis $(\mathcal{J}, \psi)$

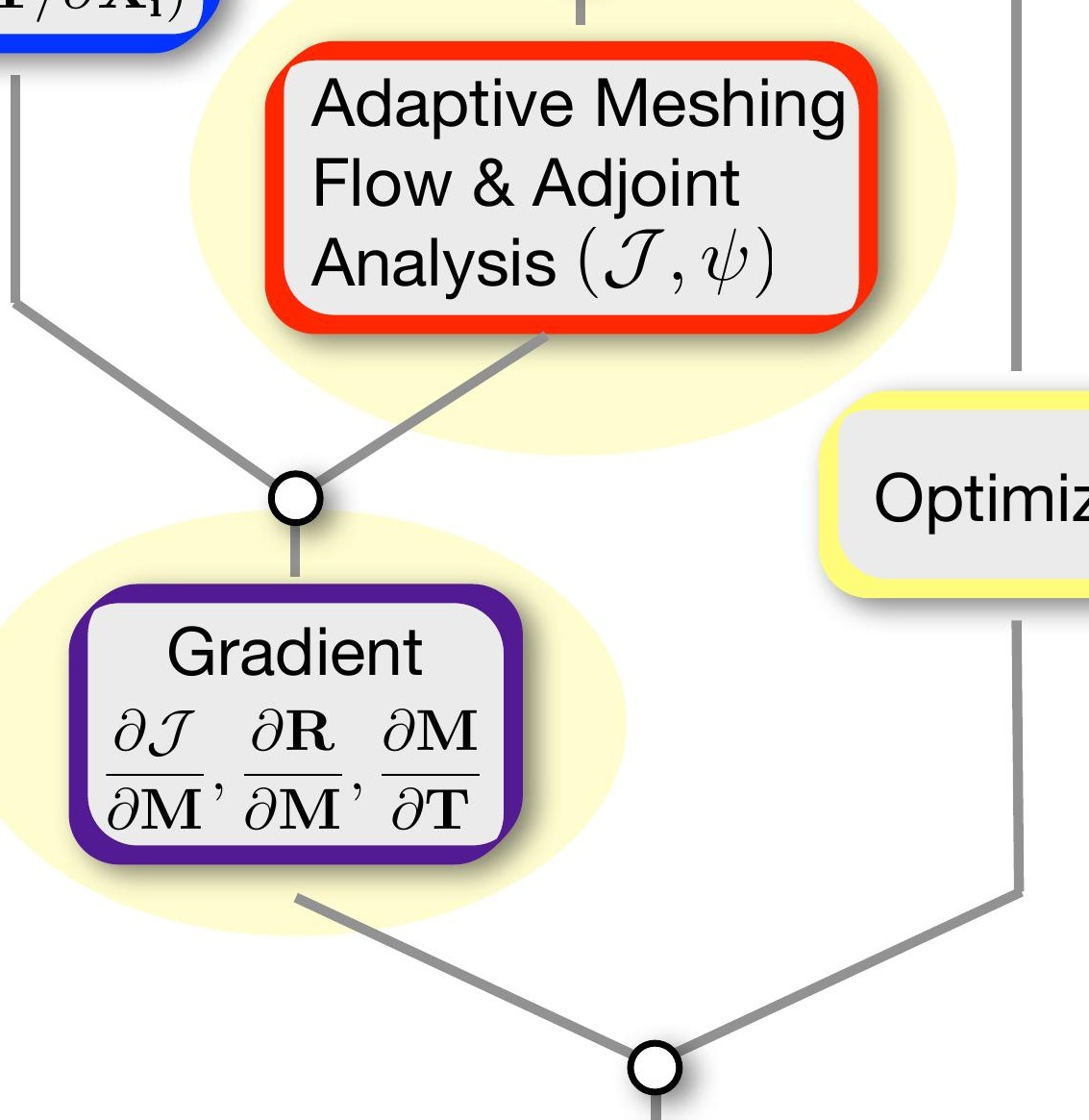




\section{Basic Example}

- Demonstrate numerical optimization with adaptive meshing

- Study mesh convergence of objective function, its error estimates and gradients

- Find angle of attack to minimize drag coefficient

- Transonic flow, $\mathrm{M}_{\infty}=0.8$

- NACA 0012 airfoil

- J $=C_{d}, X=\alpha$

- Initial design: $\alpha_{i}=2^{\circ}$ 


\section{Mesh Setup}

- Demonstrate numerical optimization with adaptive meshing

- Study mesh convergence of objective function, its error estimates and gradients

- Fixed-depth strategy

- 8 adaptive refinements at each design iteration

- Initial mesh $\sim 1,700$ cells

- Final mesh 25,000 cells

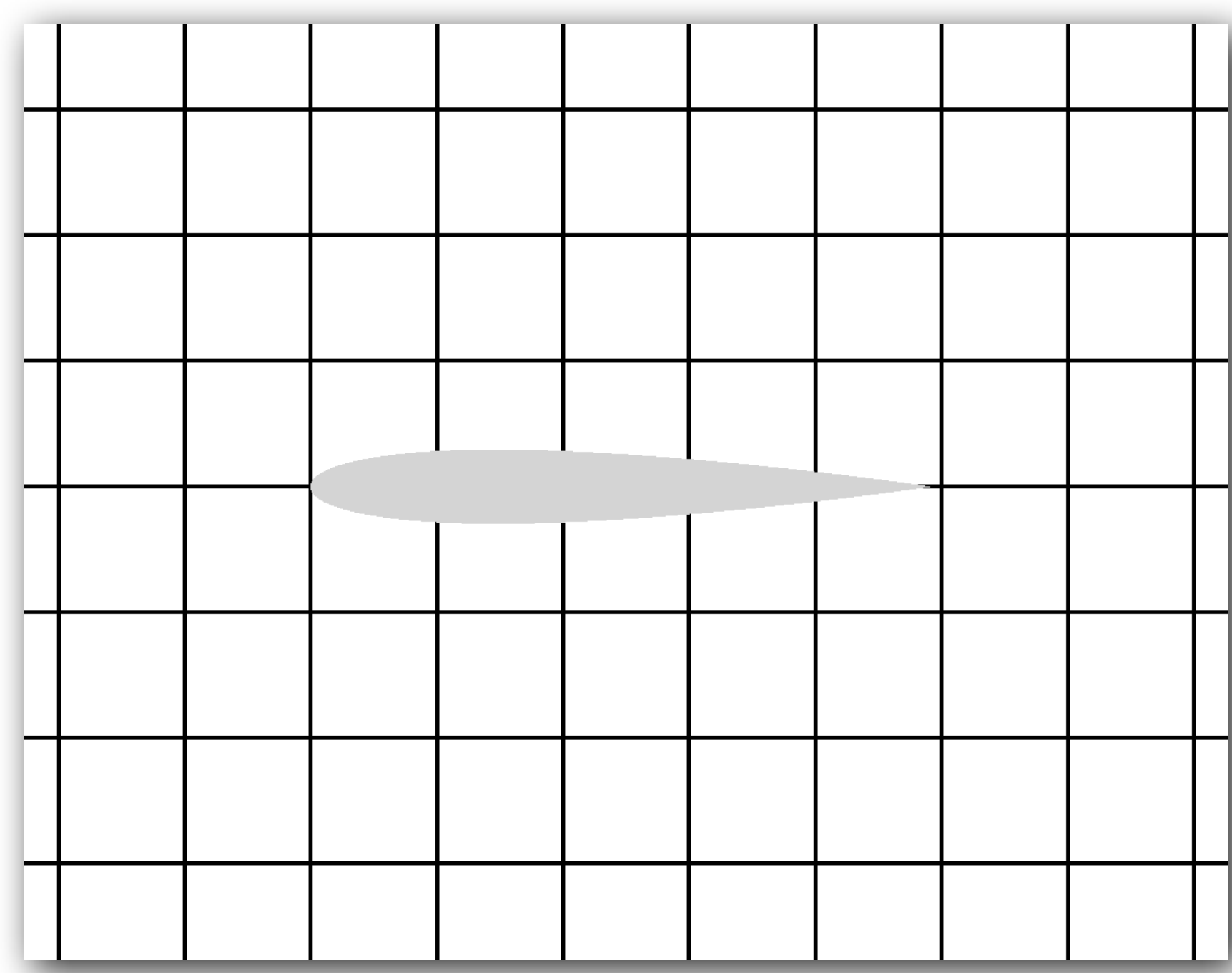

Near-field view of initial mesh 


\section{Optimization Convergence History}

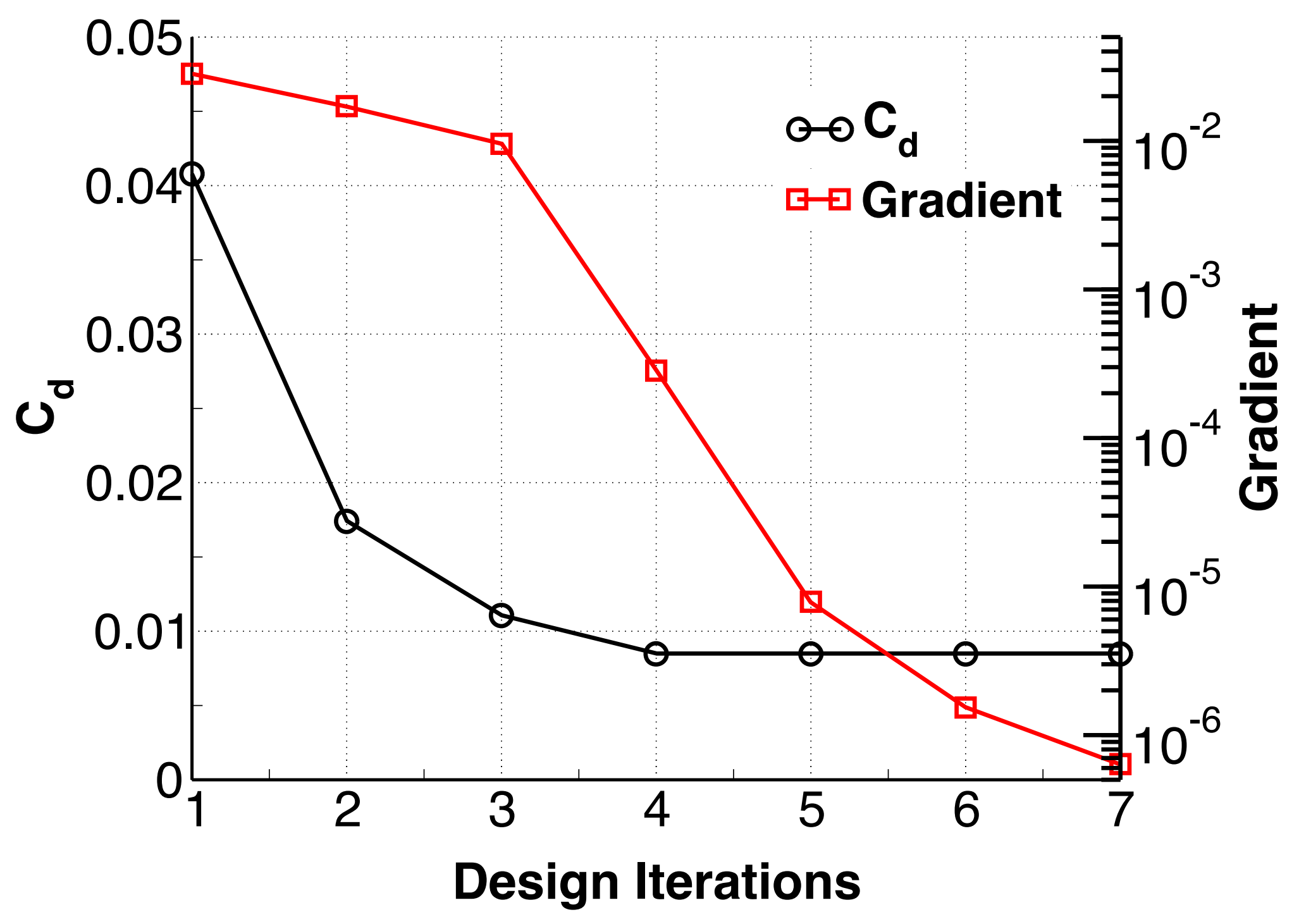

- Optimizer minimizes drag in 7 iterations

- Gradient reduced by almost 5 orders of magnitude

- Angle of attack history: $2^{\circ}, 1^{\circ},-0.5^{\circ}, 0.01^{\circ},-0.001^{\circ}$ 


\section{Final Meshes After 8 Adaptations}

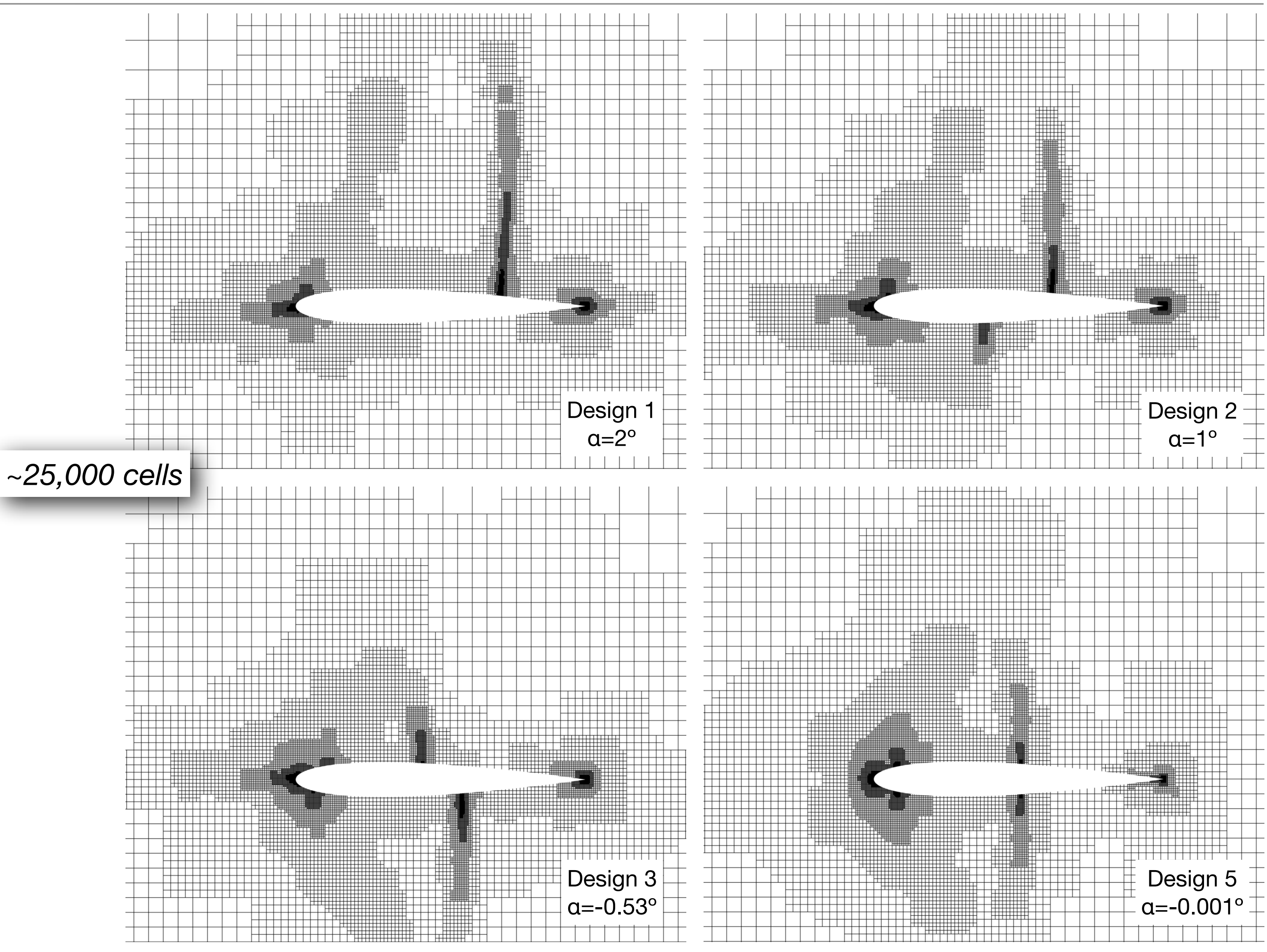




\section{Output Mesh Convergence}
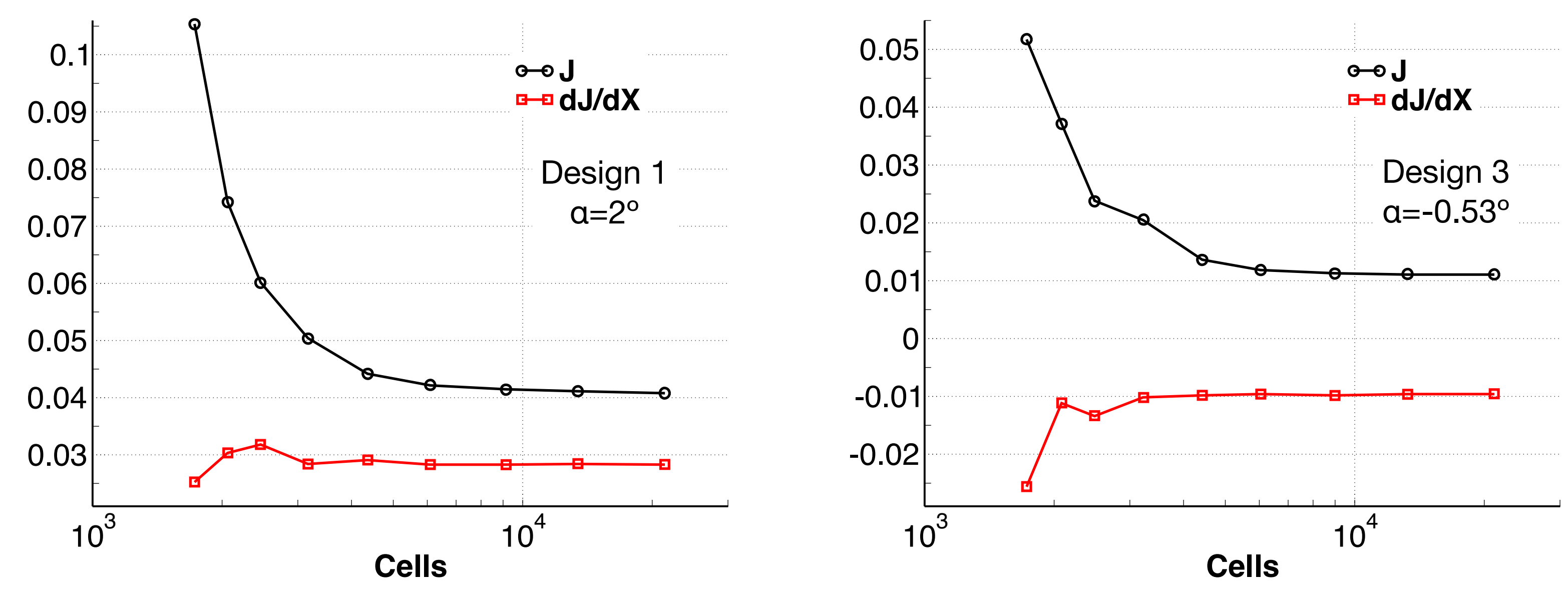

Mesh convergence of drag and gradient at selected design iterations

- Drag and gradient are well converged on meshes with 10,000 cells

- Sign predicted correctly even on the coarsest mesh 


\section{Convergence of Error Estimates}

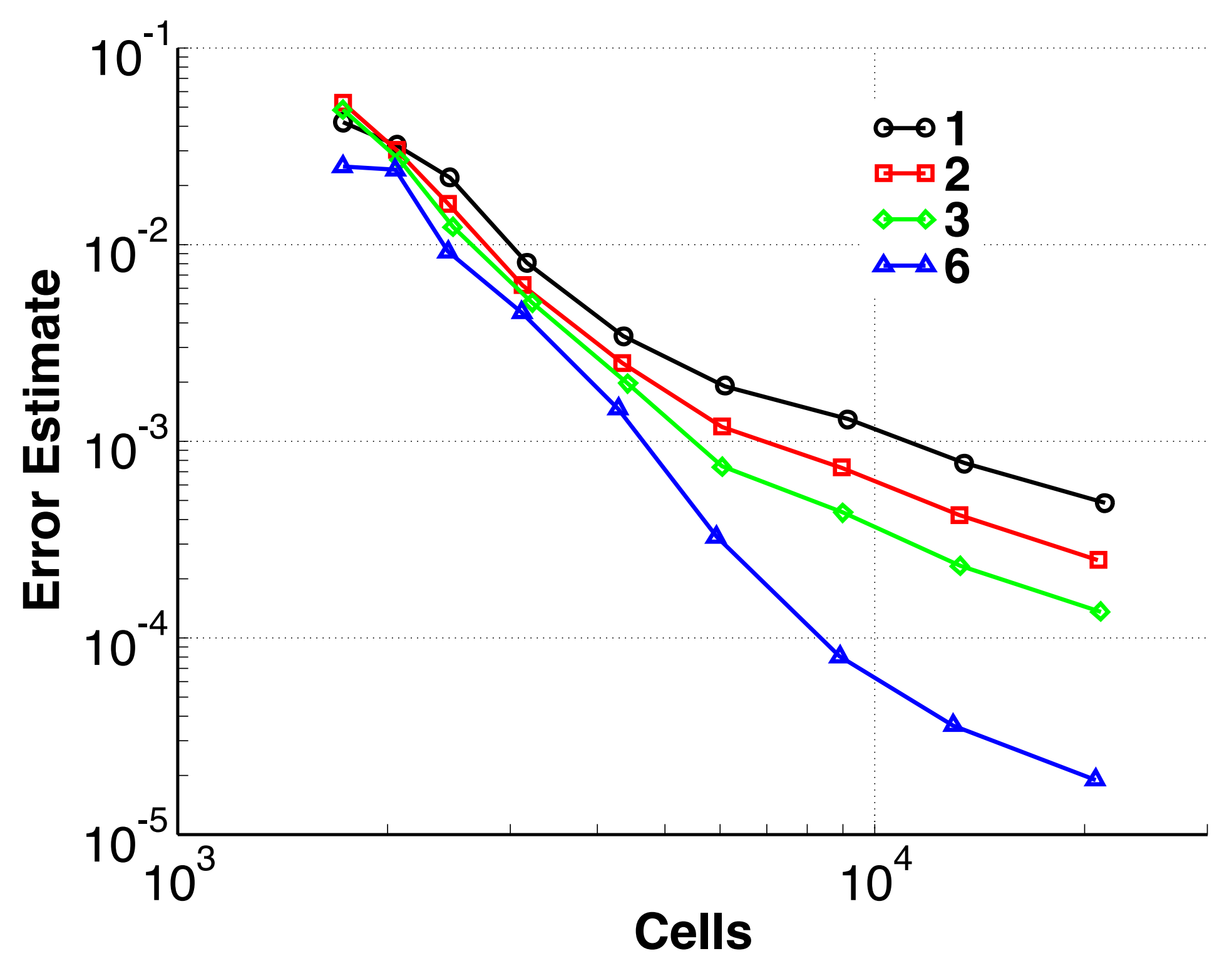

- Key parameter to safeguard oversolving and transfer optimization to next mesh 


\section{Mesh Efficiency of Fixed-Depth Strategy}

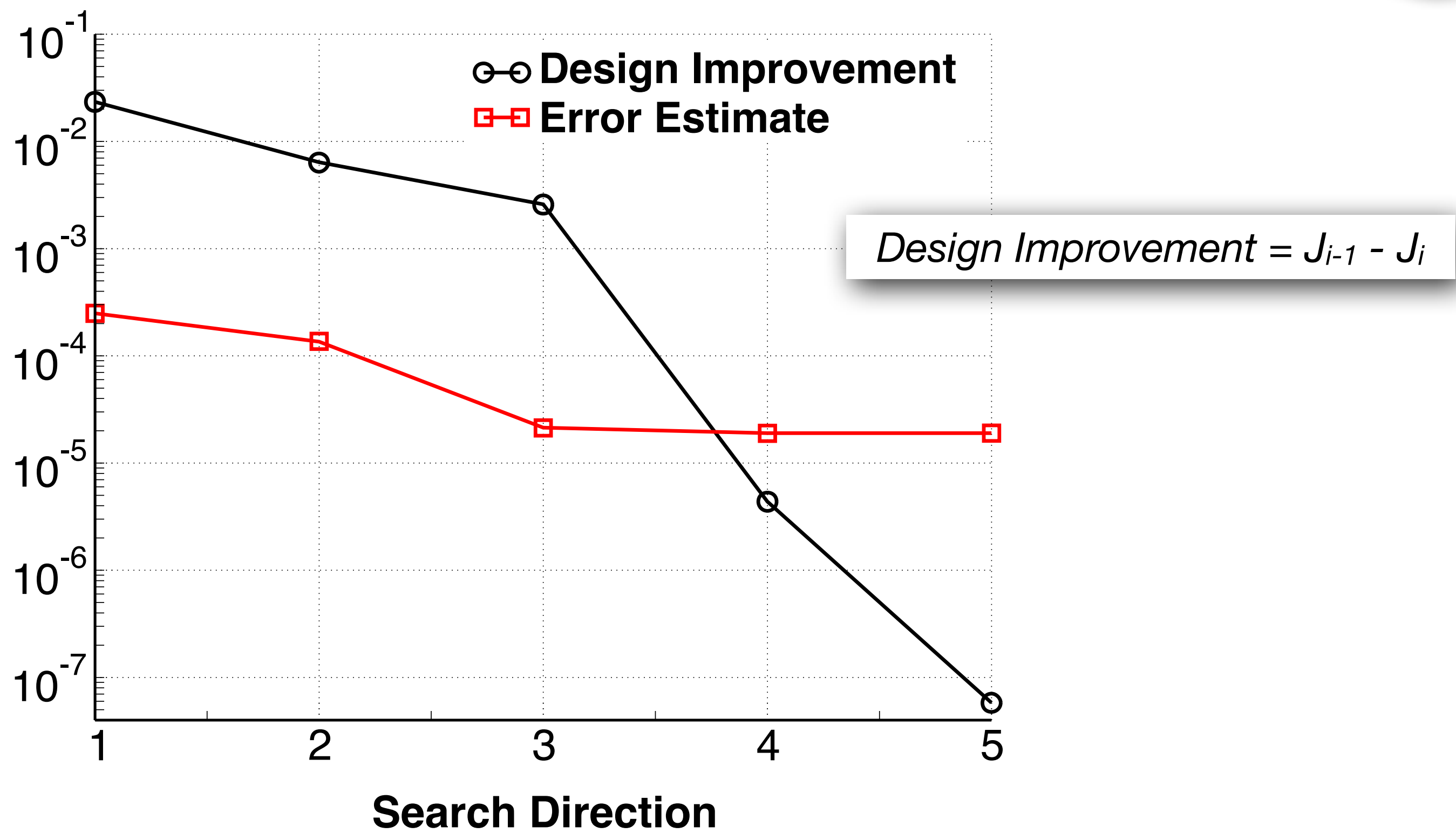

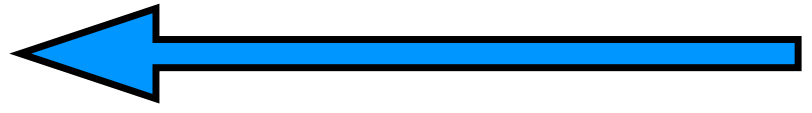

Mesh too fine

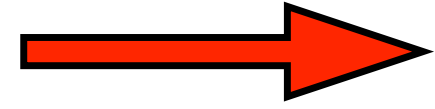

Mesh too coarse

- Angle of attack history: $2^{\circ}, 1^{\circ},-0.5^{\circ}, 0.01^{\circ},-0.001^{\circ}$ 


\section{Objectives in Quadratic Form}

- Frequently use objective functions that contain quadratic terms

- Penalty terms, e.g. $\left(C_{L}-T\right)^{2}$

- Inverse design, e.g. $J=\int\left(P-P_{\text {target }}\right)^{2} d S$

- As working variable approaches its target, adjoint variables vanish

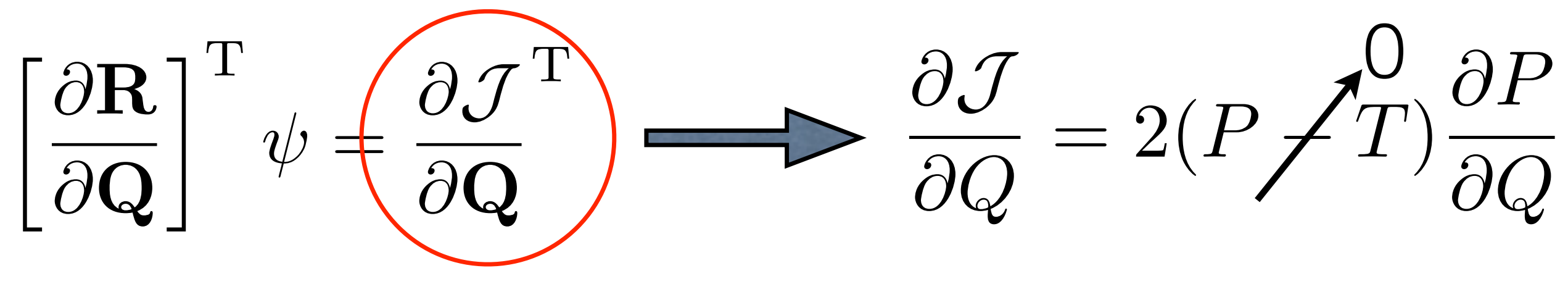

- Consequences include vanishing error estimates as optimality is approached, which effectively terminate adaptation, as well as strongly non-monotone error convergence 


\section{Quadratic Example}

- Find angle of attack to match a target lift coefficient

- Transonic flow, $M_{\infty}=0.8$

- NACA 0012 airfoil

$-\mathrm{J}=\left(\mathrm{C}_{\mid}-0.55\right)^{2}, \mathrm{X}=\alpha$

- Initial design: $\alpha_{i}=0^{\circ}$

- Final design: $\alpha_{f} \approx 2^{\circ}$

- Fixed-depth strategy

- 9 adaptive refinements at each design iteration

- Initial mesh $\sim 1,700$ cells; final mesh $\sim 35,000$ cells 


\section{Convergence Histories}
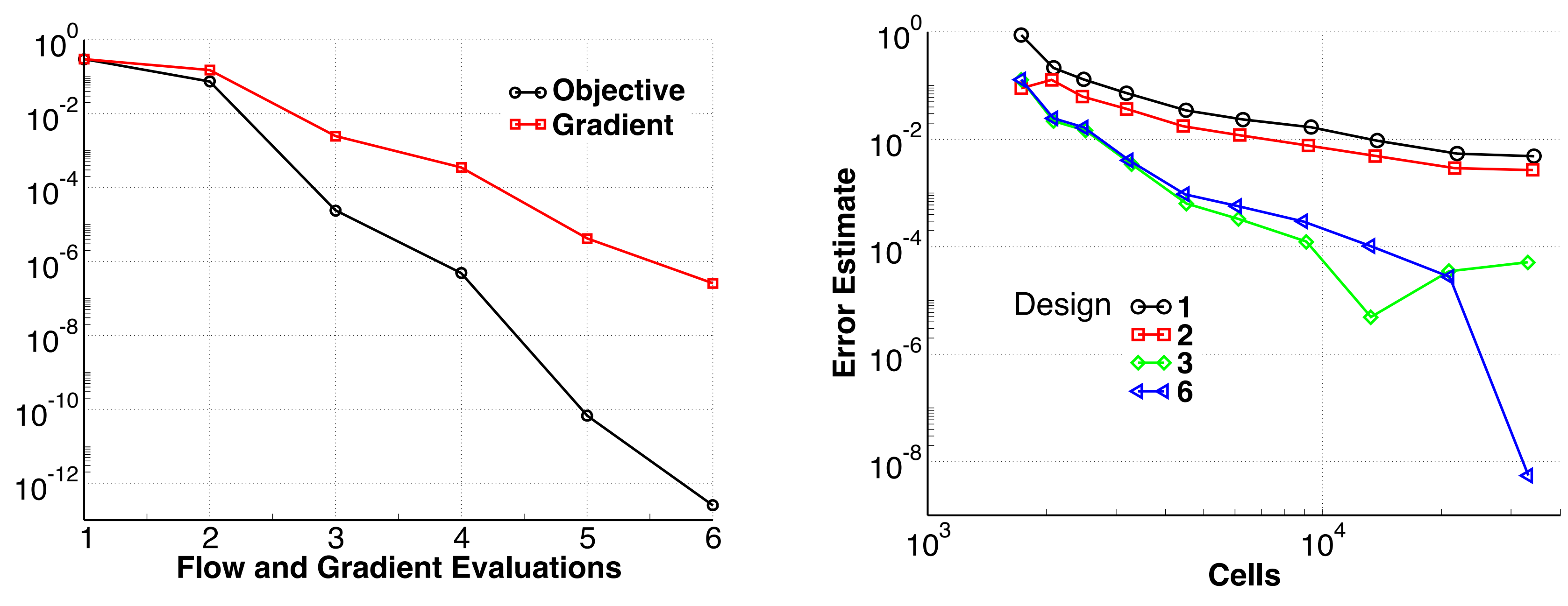

- Optimizer matches lift in 6 iterations

- Error convergence satisfactory in early design iterations, but becomes non-monotone and errors vanish at optimality 


\section{“Companion" Functional}

- Use a companion functional to eliminate numerical artifacts for quadratic objectives

- Objective function working variable is used for error control and drives adaptation

- Objective function drives design

- Possible to implement at no additional cost

- Arrange computations to use error estimates from the penultimate adaptation cycle and solve objective function adjoint only on the finest mesh 


\section{Quadratic Example}

- Find angle of attack to match a target lift coefficient

$-J=\left(C_{l}-0.55\right)^{2}, X=\alpha$

- $J_{E C}=C_{l}$, Error Estimate $=\varepsilon$

- Compute conservative error estimate in objective function

$$
\begin{aligned}
& J=\left(\left(C_{l} \pm \varepsilon\right)-0.55\right)^{2} \\
& J \leq\left(C_{l}-0.55\right)^{2} \pm \Delta \\
& \Delta=\left|2\left(C_{l}-0.55\right) \varepsilon\right|+\varepsilon^{2}
\end{aligned}
$$




\section{Quadratic Example}

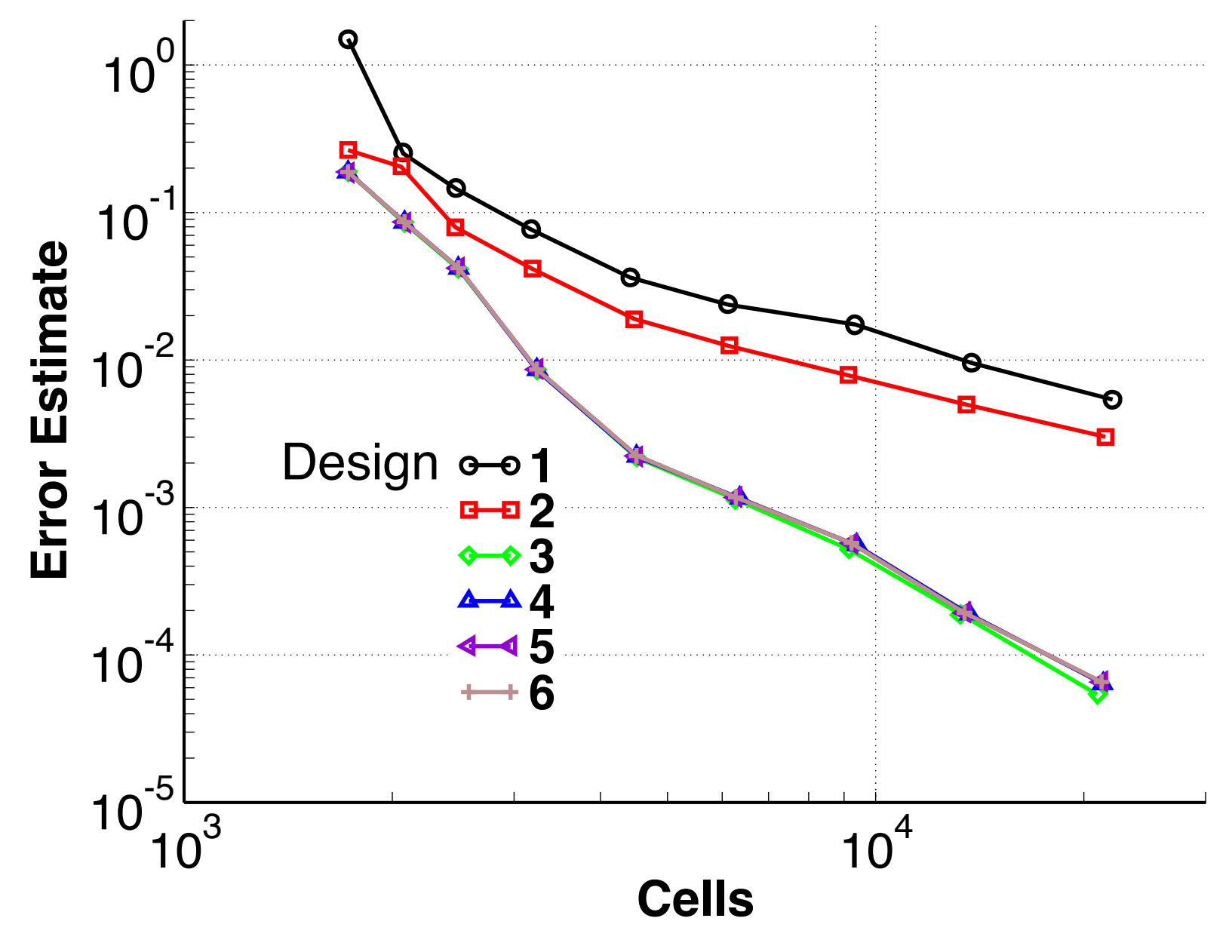

- Eliminated numerical artifact of vanishing error estimate near optimality

- Objective function error estimate smoothly decreasing in all design cycles

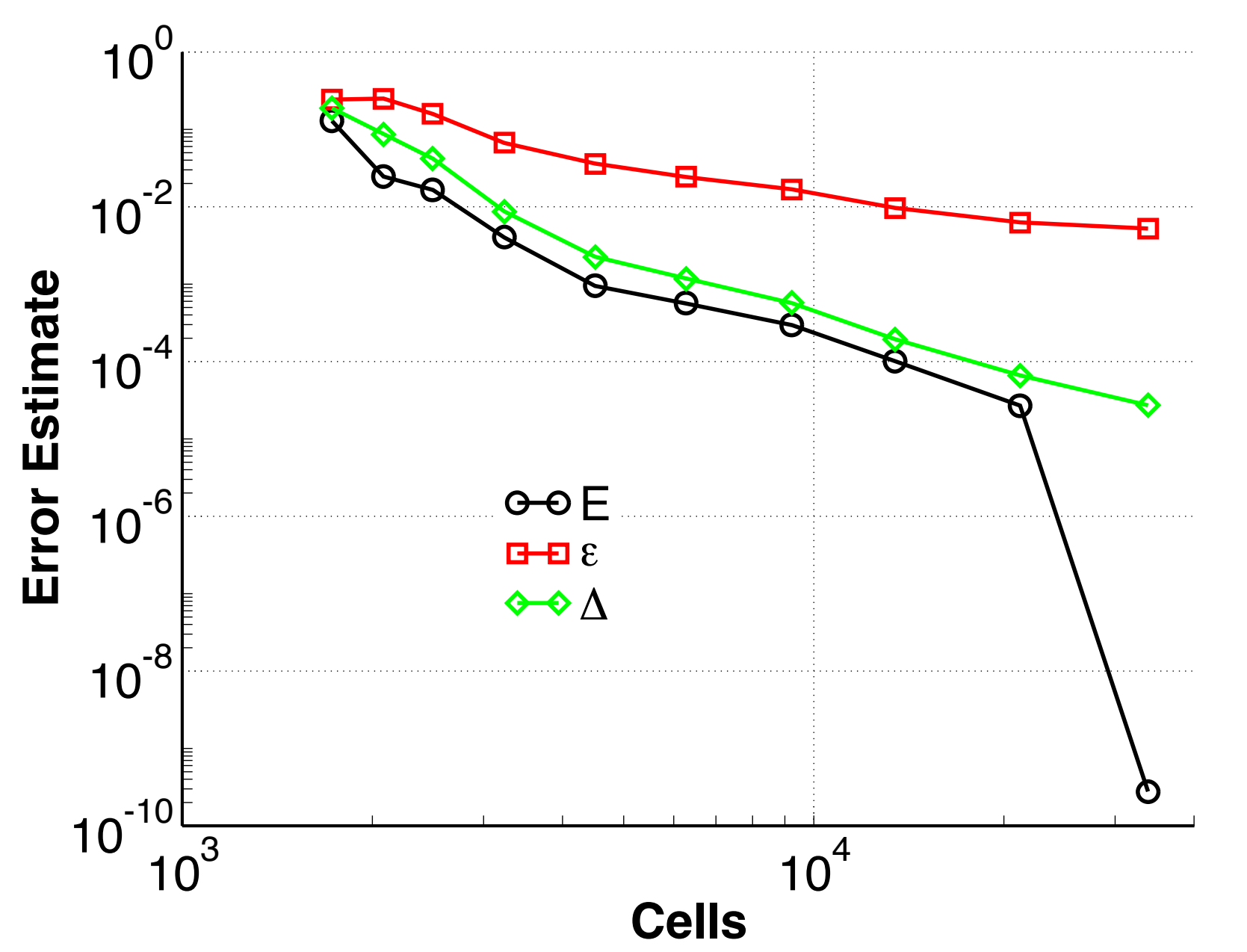




\section{Sonic-Boom Mitigation}

Drive vehicle shape by prescribing quieter near-field signals

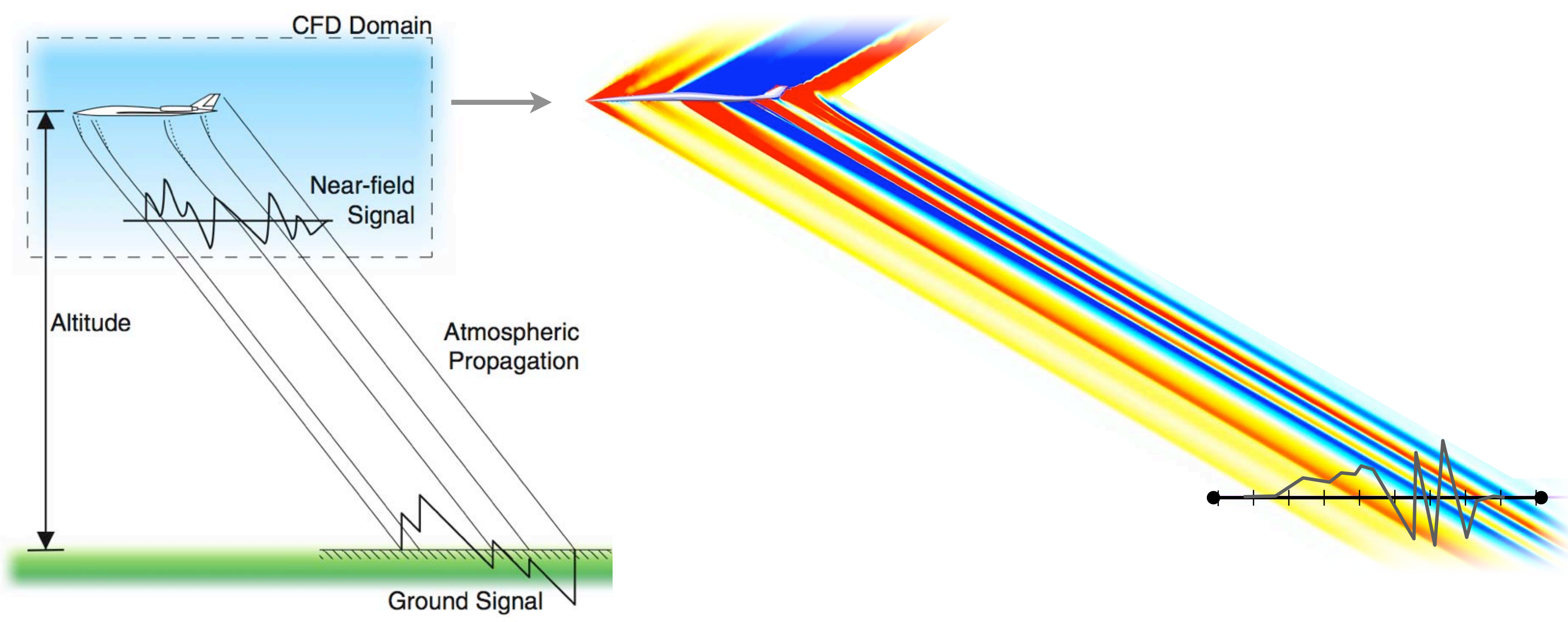




\section{Inverse Design Model Problem}

\section{Problem Setup}

- Prescribe a target signature from a known shape and verify that the optimization can recover this solution

- 10 design variables that control body radius

- $\mathrm{M}_{\infty}=1.5$ and $\alpha=0^{\circ}$

Initial Shape

Target

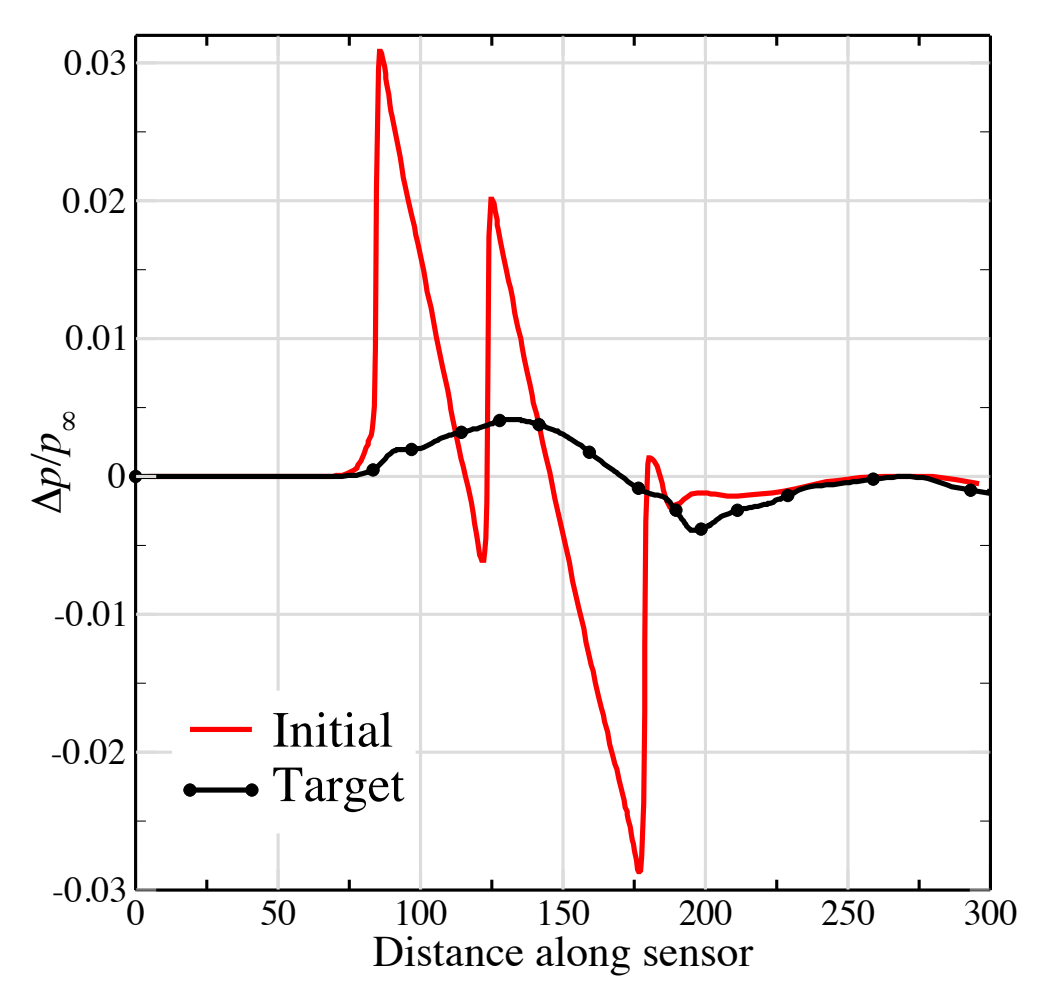




\section{Inverse Design Model Problem}

\section{Problem Setup}

- Inverse design formulation: $J=\frac{1}{p_{\infty}^{2}} \int\left(p-p_{\text {target }}\right)^{2} d S$ at $\mathrm{h} / \mathrm{L}=2$

- Error control functional: $J_{\mathrm{EC}}=\frac{1}{p_{\infty}^{2}} \int\left(p-p_{\infty}\right)^{2} d S$

- Consider two cases

1. Fixed-depth strategy: 7 adaptation cycles in each design iteration

2. Progressive optimization 


\section{Inverse Design Model Problem}

\section{Fixed-Depth Strategy}
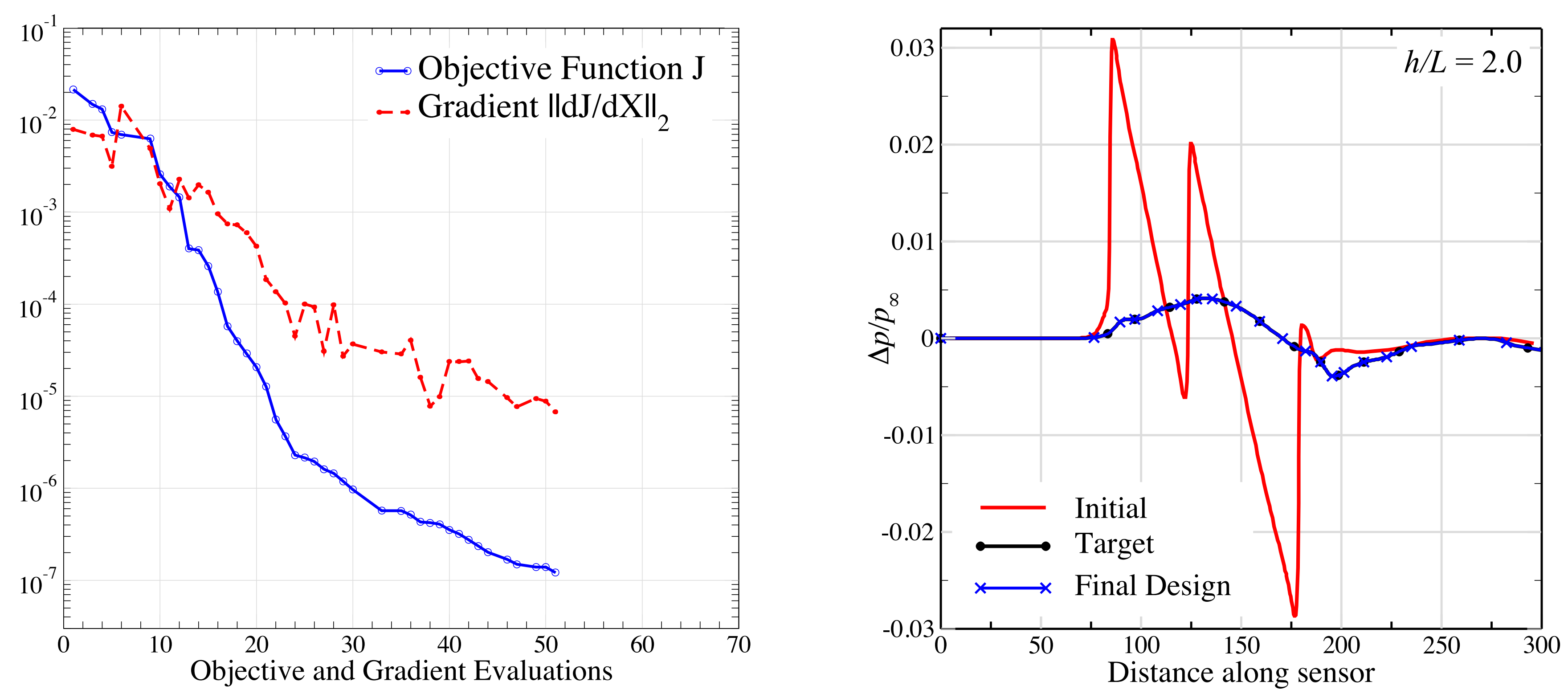


\section{Inverse Design Model Problem}

\section{Fixed-Depth Strategy}
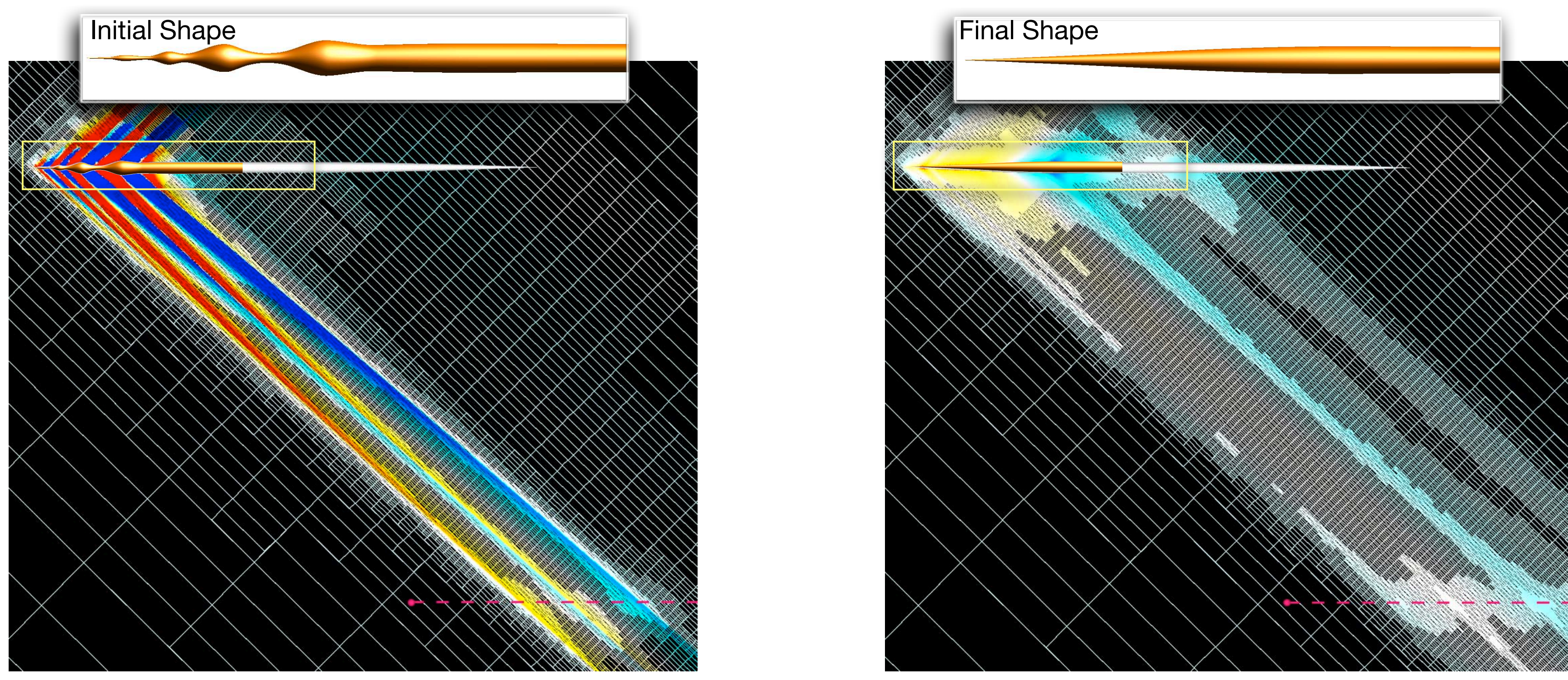

7 Adaptations, 650k cells 


\section{Progressive Optimization}

- Minimize number of design iterations performed on finest mesh

- Allow the designs to advance as far as possible on each level
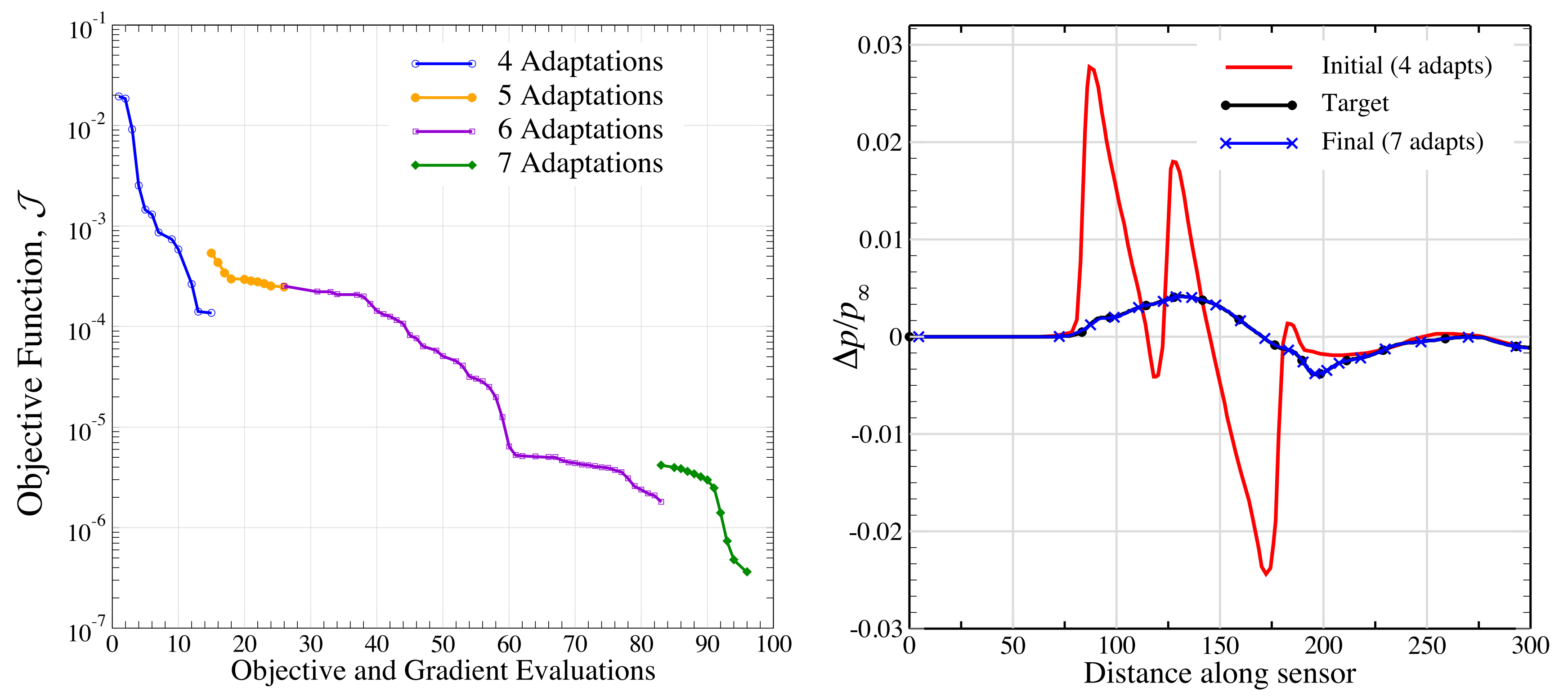


\section{Progressive Optimization}

4 Adaptations, $\sim 130 \mathrm{k}$ cells

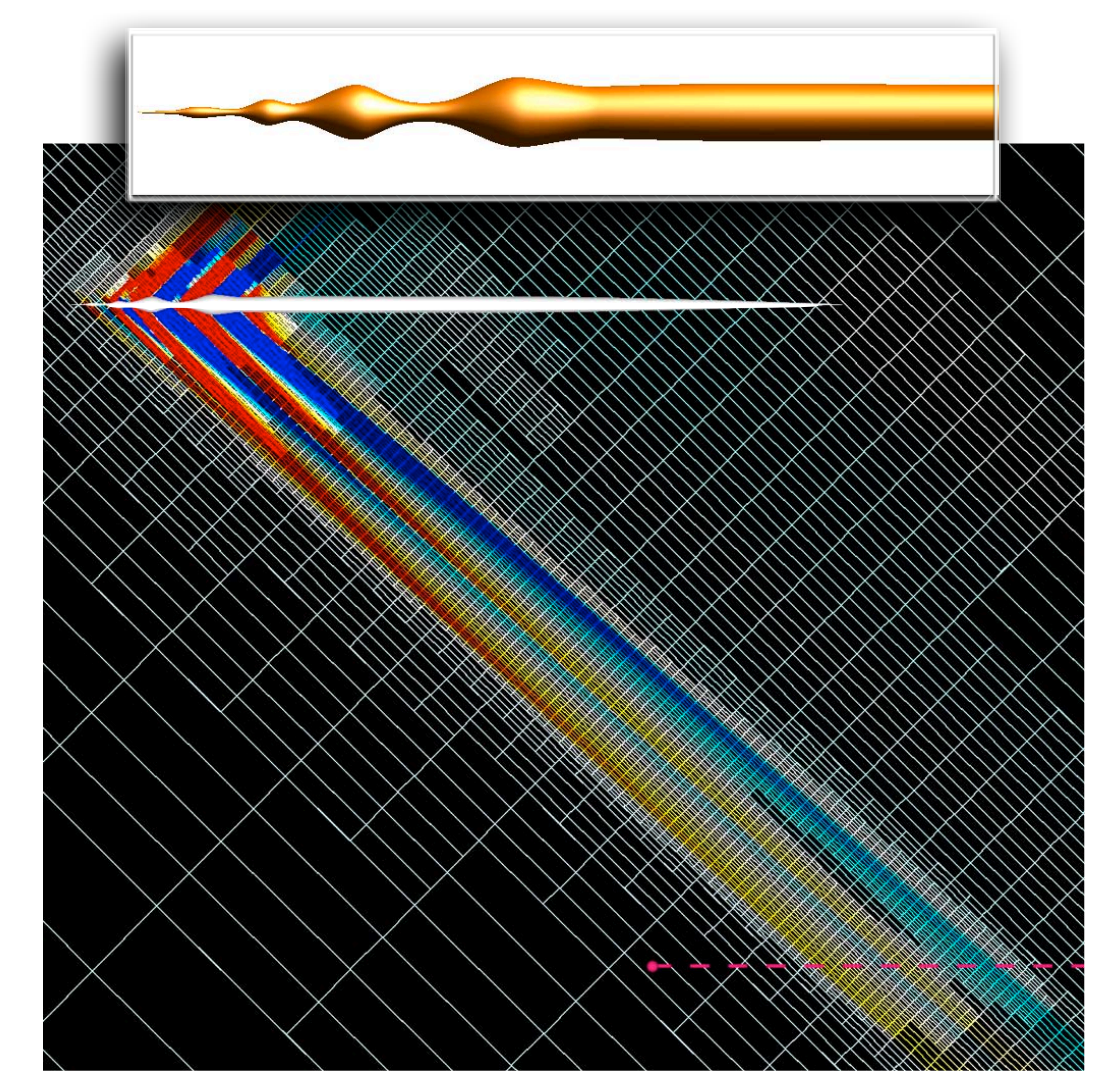

Initial, 4 Adaptations

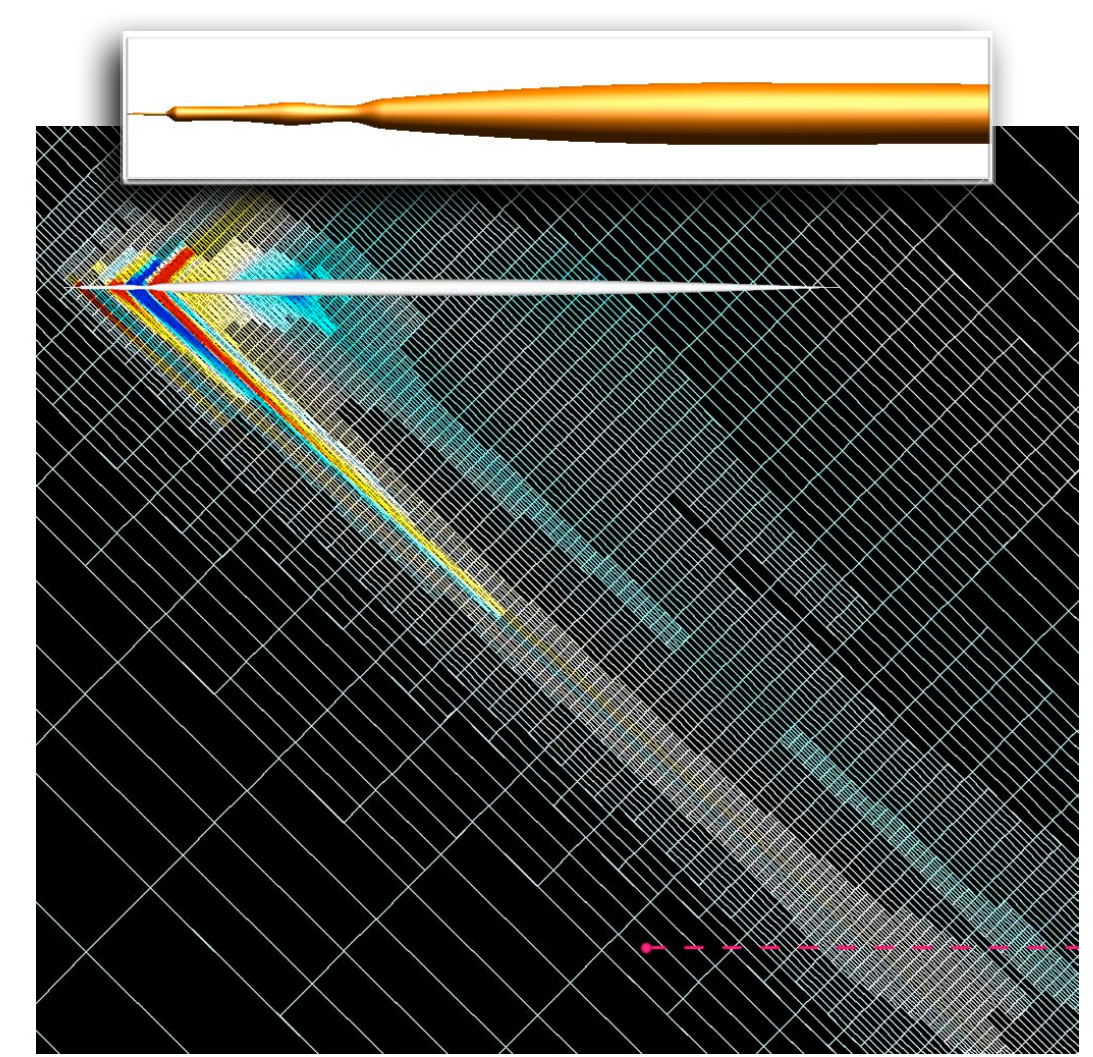

Final, 4 Adaptations

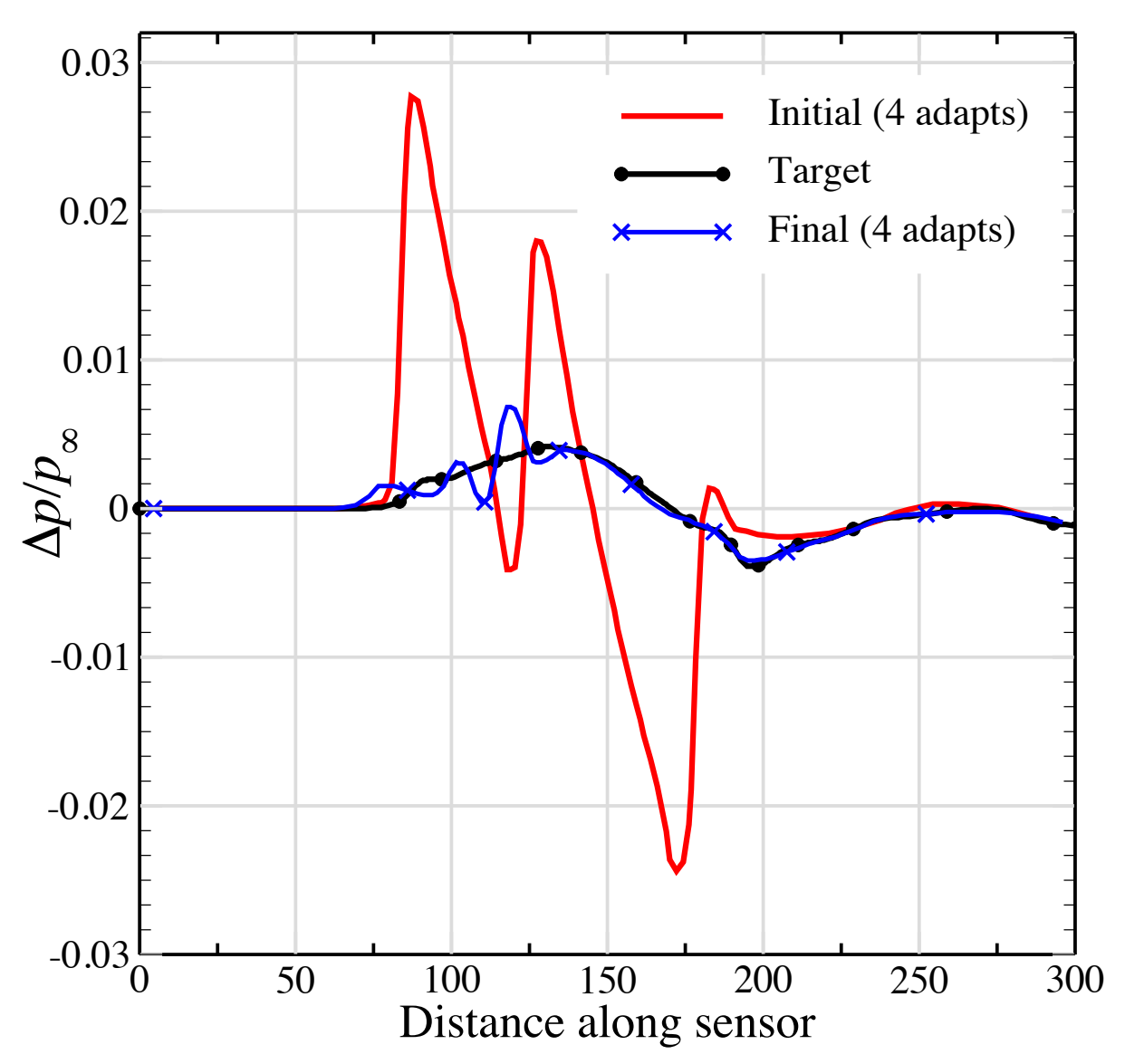

- Terminated due to design variable bound violation near nose

- Peak-to-peak signal reduced by over a factor of five, smooth aft body 


\section{Progressive Optimization}

5 Adaptations, $\sim 230 \mathrm{k}$ cells

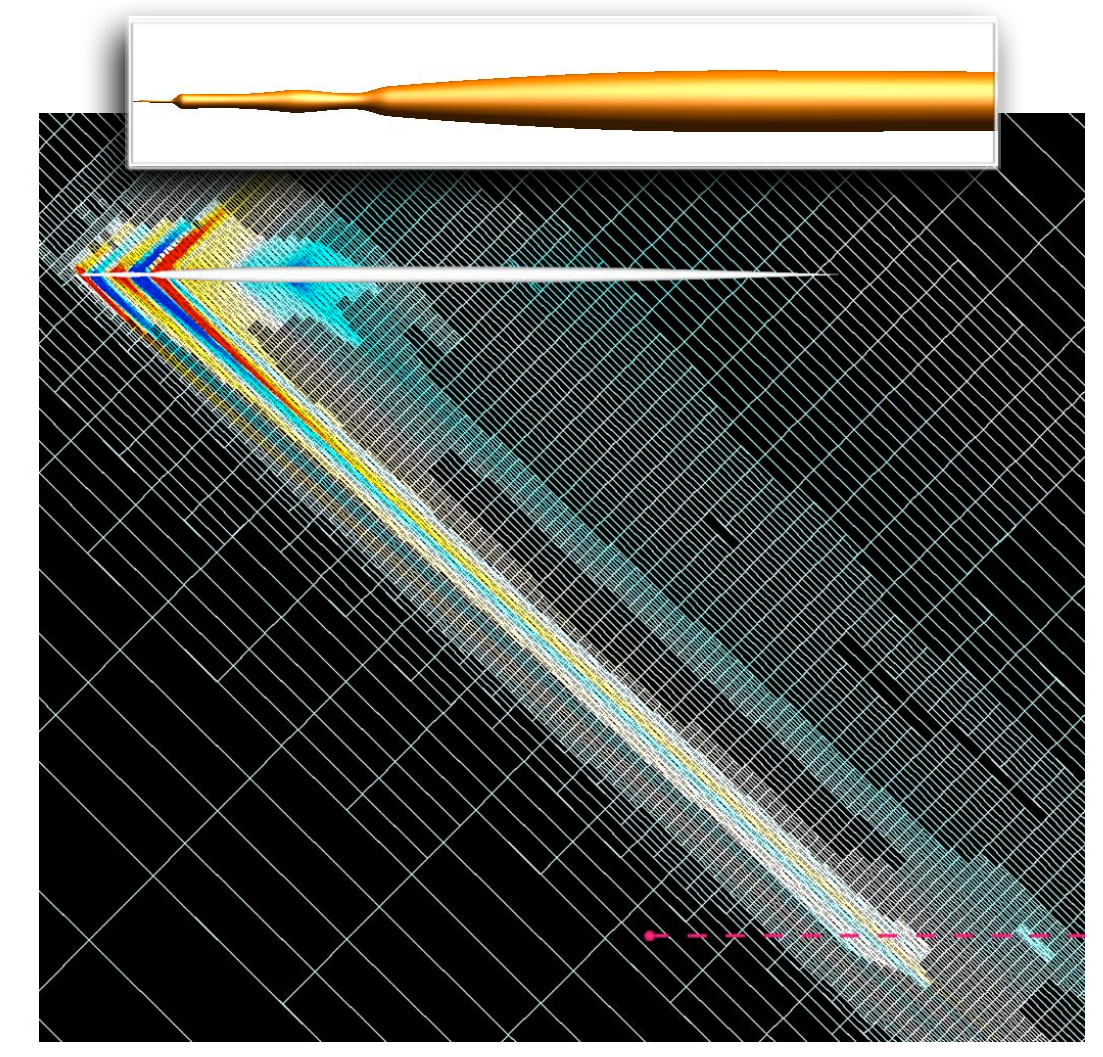

Initial, 5 Adaptations



Final, 5 Adaptations

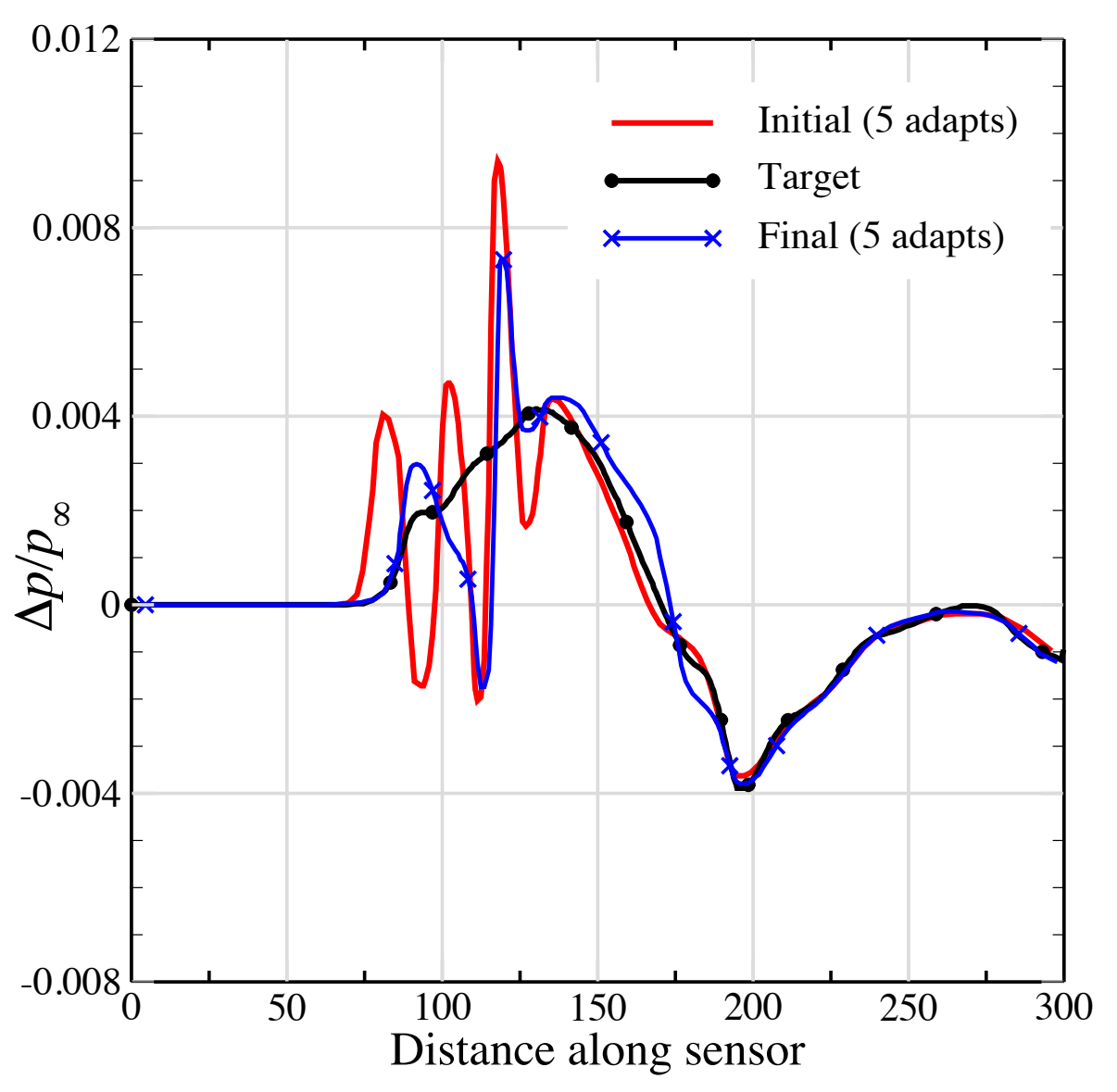

- Terminated due to design variable bound violation near nose

- Smoother nose shape, finer scales not resolvable on the previous mesh 


\section{Progressive Optimization}

6 Adaptations, $\sim 350 \mathrm{k}$ cells

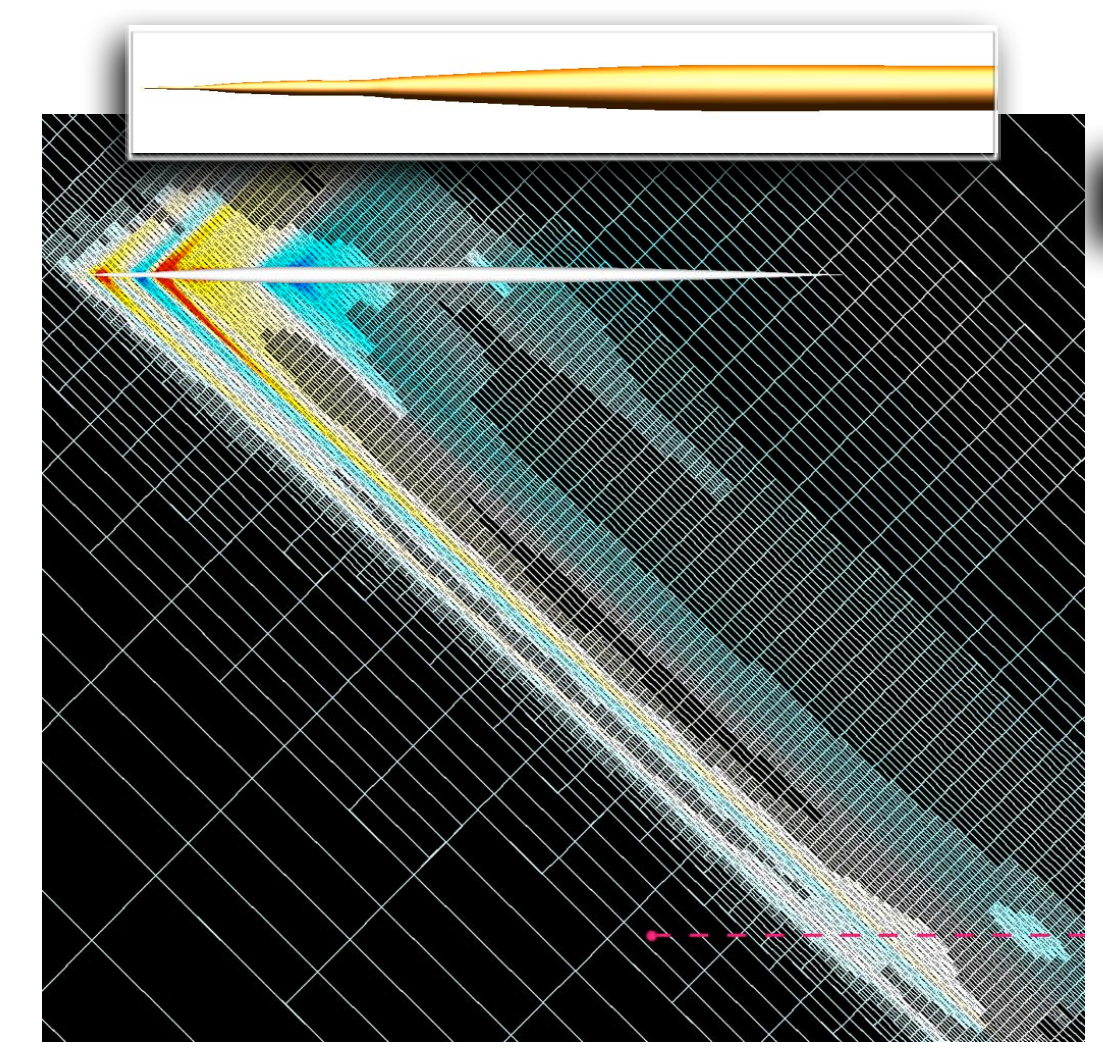

Initial, 6 Adaptations

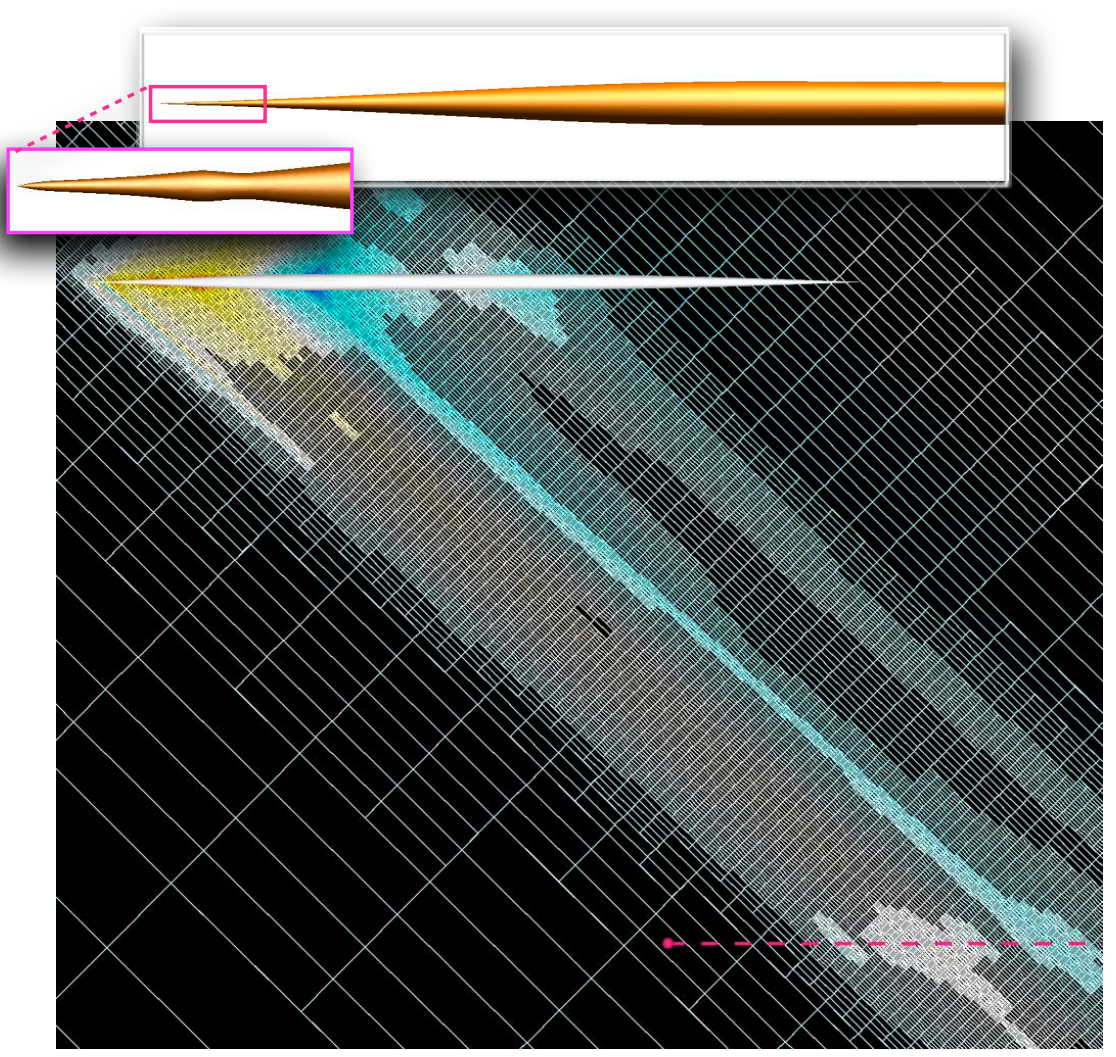

Final, 6 Adaptations

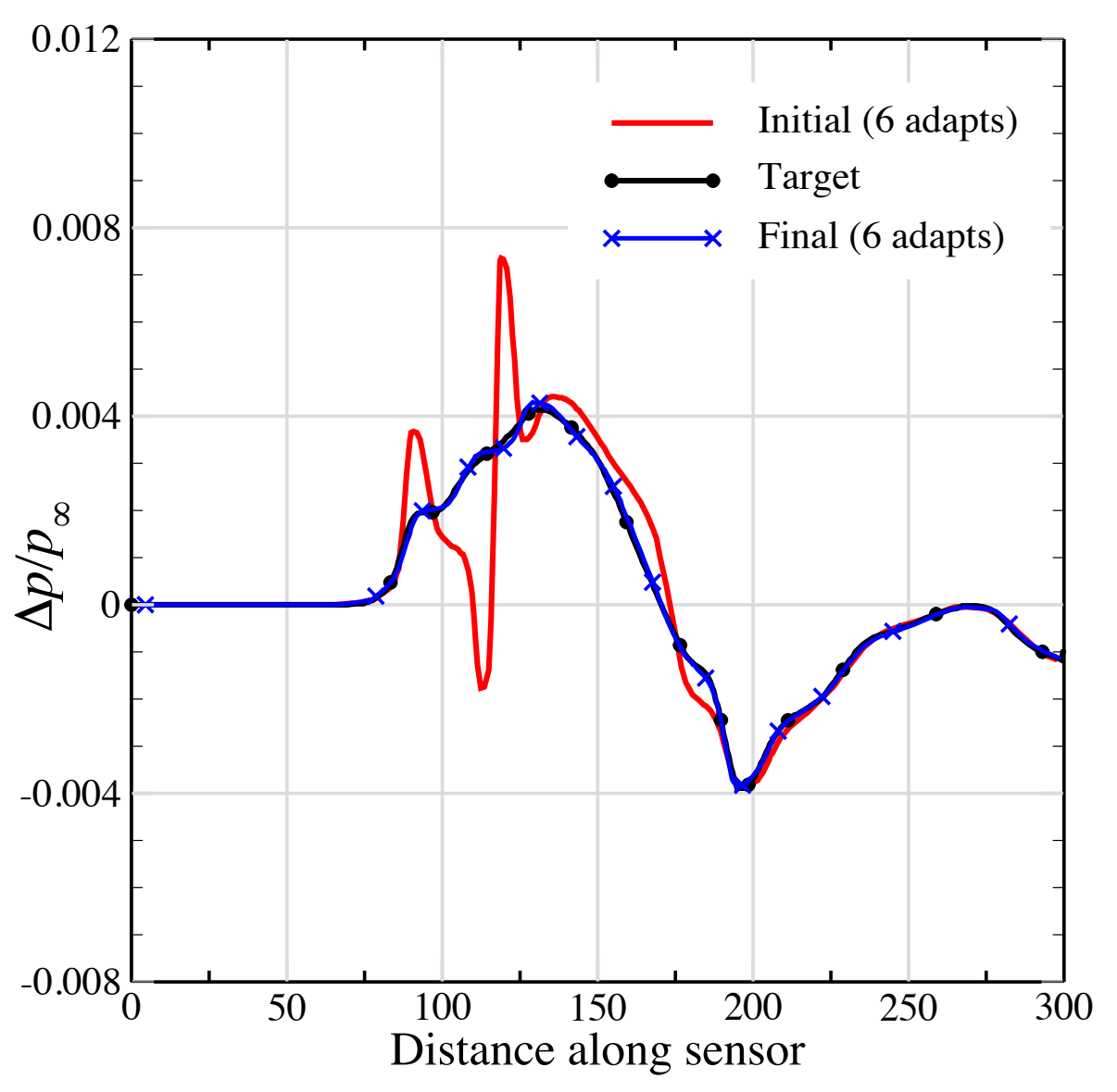

- Most work performed on this mesh: cost is roughly half of fixed-depth example per design iteration

- Target matched to plotting accuracy but tip shape different from target 


\section{Sonic-Boom Inverse Design}

7 Adaptations, $\sim 650 \mathrm{k}$ cells

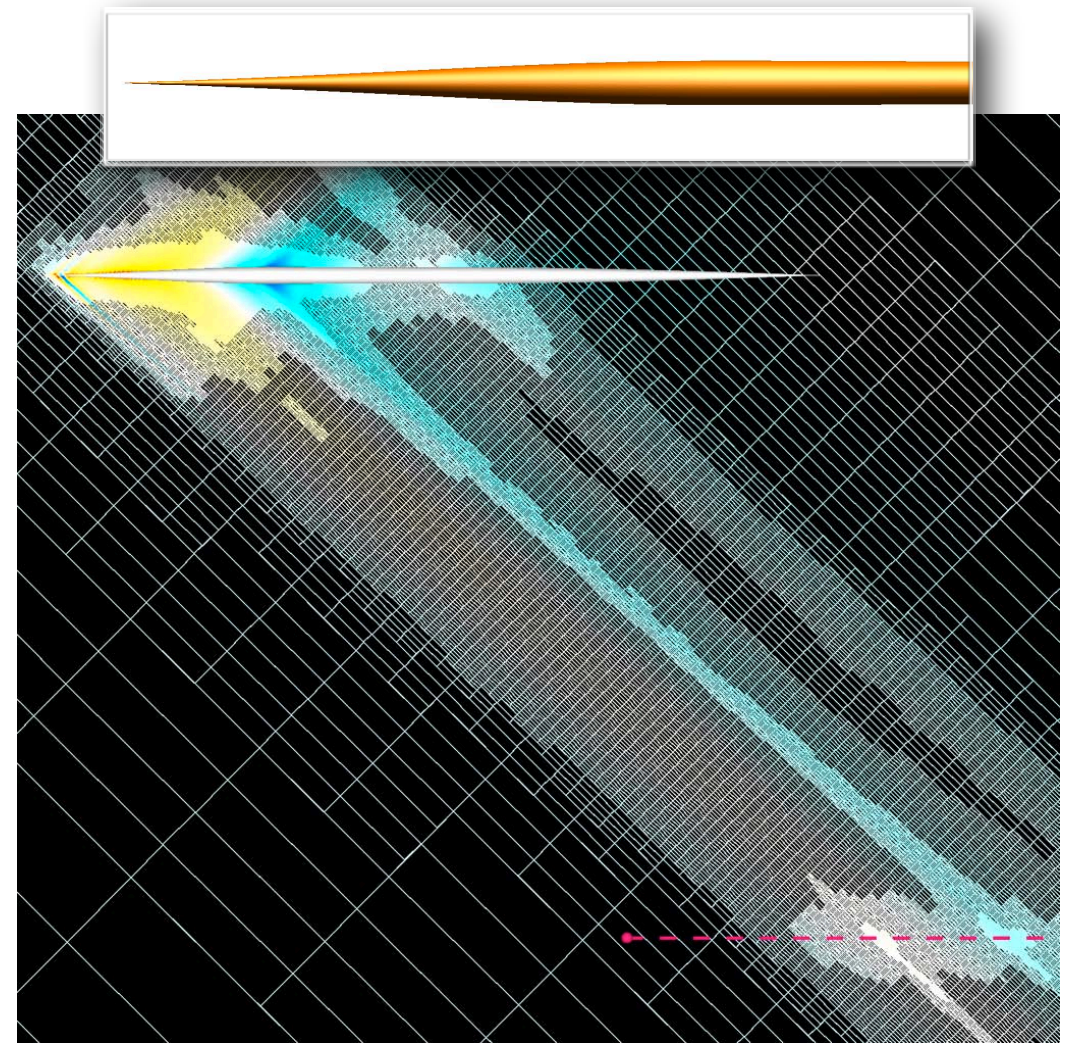

Initial, 7 Adaptations

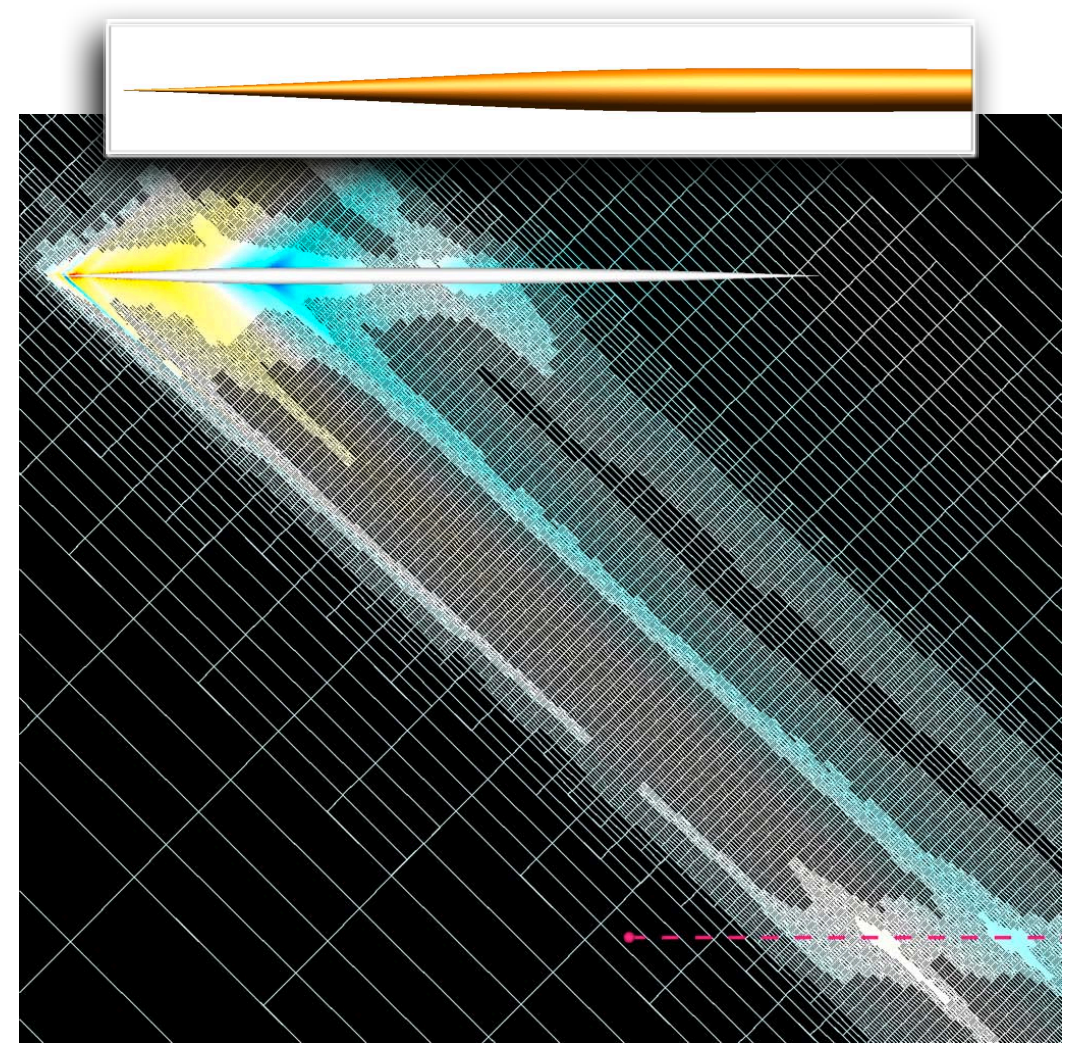

Final, 7 Adaptations

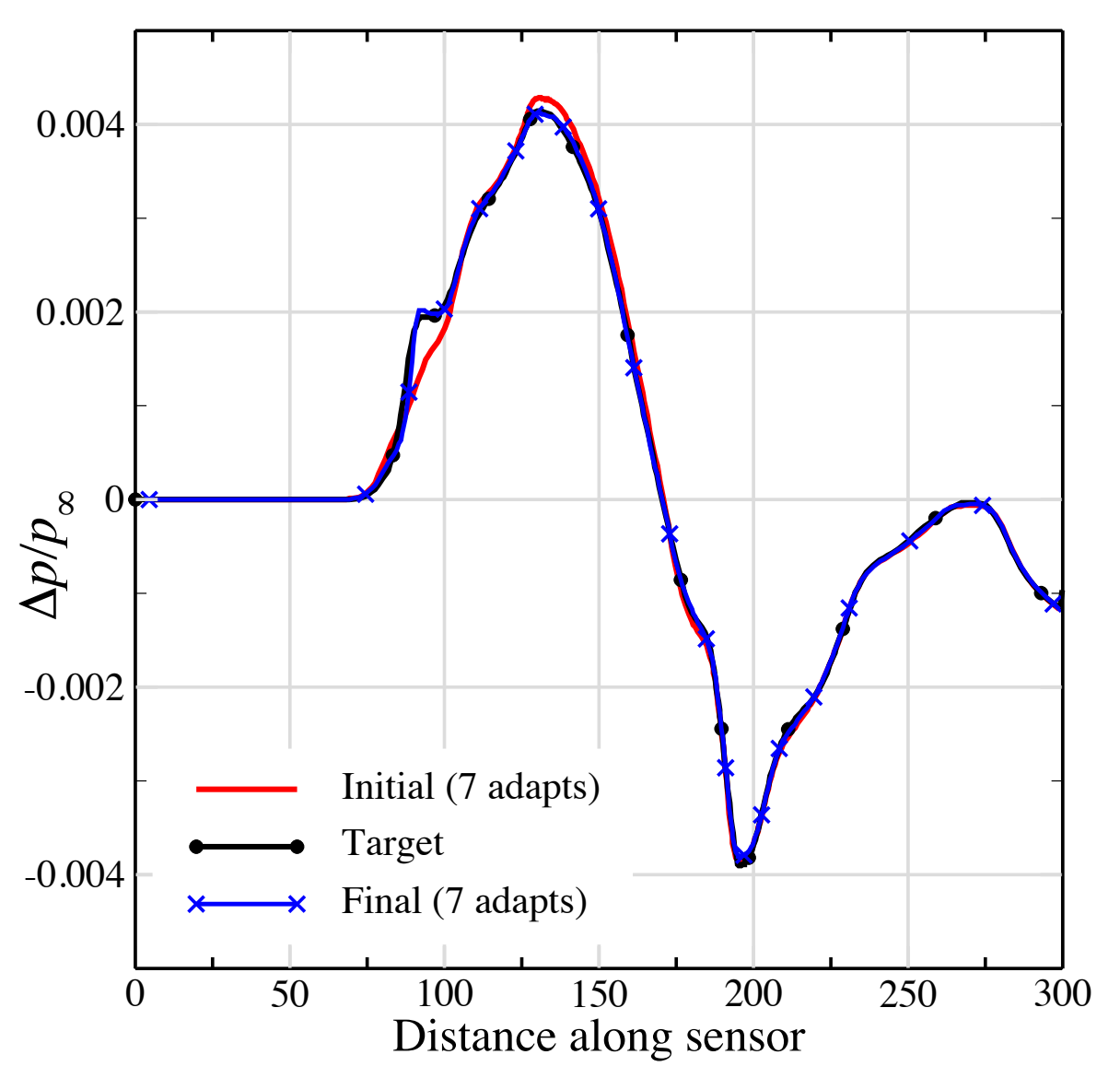

- Matched target shape in 12 design iterations

- Roughly a factor of two faster than fixed-depth strategy

- Mesh largely unchanged, could we re-use the same mesh? 


\section{Summary and Future Work}

- Developed framework for gradient-based optimization with capability to perform adaptive meshing in each design iteration

- Promising approach to enhance accuracy, efficiency and automation of simulation-based design

- Preliminary investigation of dynamic error control

- Eliminated numerical artifacts in error estimates for objective functions in quadratic form

- Future work

- Use of error estimates to limit oversolving

- Transfer of Hessian matrix as the design moves from mesh to mesh

- Mesh re-use from nearby designs 
Questions

\author{
marian.nemec@nasa.gov \\ michael.aftosmis@nasa.gov
}

